\title{
Saturable Absorption Dynamics of Highly Stacked 2D Materials for Ultrafast Pulsed Laser Production
}

\author{
Young In Jhon and Ju Han Lee *(D)
}

check for updates

Citation: Jhon, Y.I.; Lee, J.H. Saturable Absorption Dynamics of Highly Stacked 2D Materials for Ultrafast Pulsed Laser Production. Appl. Sci. 2021, 11, 2690. https:// doi.org/10.3390/app11062690

Academic Editor: Habil.

Martin Schultze

Received: 14 February 2021

Accepted: 12 March 2021

Published: 17 March 2021

Publisher's Note: MDPI stays neutral with regard to jurisdictional claims in published maps and institutional affiliations.

Copyright: (C) 2021 by the authors Licensee MDPI, Basel, Switzerland. This article is an open access article distributed under the terms and conditions of the Creative Commons Attribution (CC BY) license (https:// creativecommons.org/licenses/by/ $4.0 /)$.
School of Electrical and Computer Engineering (Brain Korea 21), University of Seoul, 163 Seoulsiripdae-ro, Dongdaemun-gu, Seoul 02504, Korea; yijhon@uos.ac.kr

* Correspondence: j.h.lee@ieee.org

\begin{abstract}
This review summarizes recent developments of saturable absorbers (SAs) based on 2D materials for nonlinear optical absorption and ultrafast pulsed laser generation. Apart from graphene, various 2D materials such as topological insulators and transition metal dichalcogenides are investigated for SA applications and their important potential as passive mode-lockers for femtosecond laser production are extensively investigated. By selecting appropriate 2D materials, a wide spectral range of passively mode-locked pulsed lasers are obtained, covering visible, midinfrared and a terahertz region. A set of different approaches is used for fabricating SA modules of fiber laser photonics, which include sandwiching, side-polishing and tapering methods. Noticeably, through systematic studies, it is demonstrated that layer-stacking seldom deteriorates the SA performance of 2D materials in the evanescent regime, although their ultrathin nature may improve the efficiency in a transmission mode like sandwich-type SAs. The direction for designing new SAs is presented based on material characterization.
\end{abstract}

Keywords: 2D materials; photonics; nonlinear optics; saturable absorber; femtosecond lasers

\section{Introduction}

Along with ever-growing laser technologies, nonlinear optics has occupied one of the most important areas in modern photonics [1]. This discipline deals many interesting phenomena such as optical rectification, two-photon absorption, four-wave mixing and saturable absorption [2-5]. Nonlinear optical absorption occurs from saturable absorption in which absorption of light decreases as incident light intensity increases. After an infant stage of saturable absorbers (SAs) based on organic dyes, semiconductor SA mirrors (SESAMs) using inorganic compounds have been predominantly employed in commercialized devices for production of passively mode-locked and/or Q-switched pulsed lasers [6].

After the discovery of graphene, many new kinds of 2D nanomaterials have been developed and intensively investigated for their applications to photonic engineering in parallel with studies using conventional nanomaterials [7-11]. These post-graphene 2D materials are transition metal dichalcogenides (TMDCs), topological insulators (TIs), phosphorene, MXenes and so on [12-20]. Graphene exhibits exotic mechanical fractures [21] with intriguing tensile orientation dependence [22] and exceptional mechanical strength with remarkable stretchability [23], which can be used in ultrathin membrane technologies [24,25]. MXenes show predictable and substantial mechanical variation depending on surface termination states, indicating tailorable mechanical applications. Meanwhile, TMDC 2D materials provide promising excitonic photoluminescent platforms with controllable brightness via chemical means [26,27] and offer a wide range of 2D semiconductors suitable for wearable electronics and future energy harvesting technologies [28].

Recently, enormous efforts have been paid to the development of novel SAs based on 2D materials, which include graphene, 2D TIs, graphene oxides, topological semimetal, TMDCs, transition metal monochalcogenides and MXenes [29-46] and the research on 
this field presented many noteworthy results, from which compact, high-performance photonic devices were successfully fabricated for optical switching and ultrafast pulsed laser production. Particularly, fiber laser optics based on SAs has many useful features in terms of reliability, compactness and beam quality, compared to free-space lasers. Regarding the spectra range, $2-3-\mu \mathrm{m}$ infrared laser technology has become one of the most important photonic areas for military and medical applications because light sources with the wavelengths of $2 \mu \mathrm{m}$ and beyond are most suitable for medical laser application, micromachining and light detection and ranging (LIDAR).

This review summarizes recent progresses in developing 2D material based SAs, focusing on the stacking effect and spectral application issue. In the following second chapter, we first introduce parameters for quantitative evaluation of saturable absorption and conceptualize mode-locking phenomenon in laser optics. In the third and fourth sections, the promising saturable absorption and mode-locking performance of highly stacked 2D TMDCs and TIs are investigated, respectively. Noticeably, generation of pulsewidth controllable dissipative solitons can be achieved using highly stacked $\mathrm{Bi}_{2} \mathrm{Te}_{3} \mathrm{TIs}_{\text {, }}$ and the importance of TI SAs in midinfrared laser technologies is highlighted. In the fifth chapter, graphene and graphite are comparatively studied for SA-based laser modulation. Different from evanescent cases, possible merits of a graphene SA over a graphite SA were discussed for sandwiched-type applications. In the final chapter, we summarize the results and present the perspective of 2D material SAs in laser technologies.

\section{Saturable Absorption and Mode Locking}

Saturable absorption is one of nonlinear optical phenomena in which optical absorption decreases as incident light intensity increases, which can be explained by excited electron dynamics and Pauli's blocking principle. Pauli blocking occurs when the transition states are filled, hence an incoming electron can no longer jump to them as a direct result of the Pauli exclusion principle. Consequently, saturable absorption takes place when a high intensity light comes into SAs. Higher is the incoming light intensity, more easily it can pass through SAs. In contrast, a low intensity light does not induce such a physical event and the incoming low intensity light would be absorbed into SAs and not allowed to pass through SAs.

As such in most nonlinear optical processes, sufficiently high incident light is required to trigger saturable absorption. The physical parameters of SA are for how fast it dynamically responds, at what intensity it saturates and for what wavelengths it absorbs, which correspond to a recovery rate, saturation intensity and spectral range of application, respectively. A typical nonlinear optical absorption curve for characterization of saturable absorption is shown in Figure 1, in which several important parameters are presented. SAs show prominent intensity-dependent optical loss $\alpha(I)$, exhibiting a curve shown below.

$$
\alpha(I)=\frac{\alpha_{o}}{1+I / I_{o}}+\alpha_{n s}
$$

where $\alpha_{n s}$ is a non-saturation component of optical loss and $\alpha_{o}$ is a total optical loss difference, and $I_{0}$ is a saturable intensity.

In laser optics, a high intensity light can occur when the modes of propagating lights in the cavity are accidentally locked in phase. As the saturable absorption process repeats by SAs, eventually lasers with a significantly high intensity would only survive in the cavity and they would correspond to highly mode-locked pulsed lasers, which is referred as passive mode-locking. In this context, ultrafast pulse lasers can be generated through a mode-locking process. At a mode-locking state, relative phases of laser modes in a cavity are locked and these modes are periodically constructive with one another, generating an intense pulsed laser. The duration of the pulsed laser is determined by the number of modes that are oscillating in phase and its time-bandwidth product is associated with the pulse shape. 


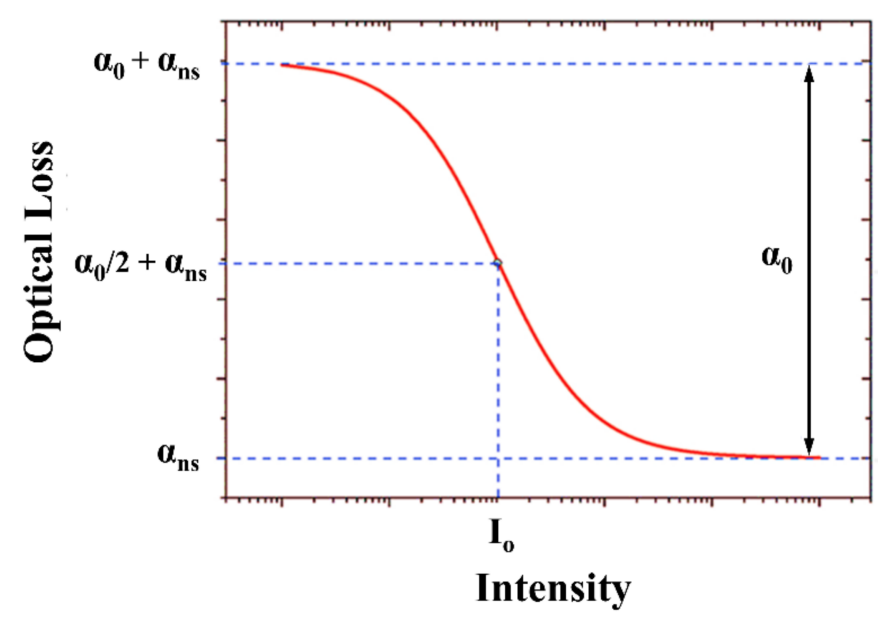

Figure 1. Saturable absorption curve with parameters for characterization.

For example, a hyperbolic-secant-squared shape is often assumed for ultrashort fiber pulse lasers and its time-bandwidth product is 0.315 . Passive mode-locking can be easily obtained using SAs and excellent SA performance enables the production of femtosecond pulsed laser in a compact photonic platform.

\section{Transition Metal Dichalcogenide SAs}

3.1. Few-Layered $\mathrm{MoTe}_{2} / \mathrm{WTe}_{2} \mathrm{SAs}$

TMDCs with chemical formula $\mathrm{MX}_{2}$ where $\mathrm{M}$ is a transition metal (Mo, $\left.\mathrm{W}\right)$ and $\mathrm{X}$ is a group VI element $(S, S e, T e)$ are one important family of 2D materials. The monolayer structure of 2D TMDCs is composed of two hexagonal planar arrangements of $X$ atoms and the in-between plane of $\mathrm{M}$ atoms. The $\mathrm{M}$ atoms are covalently bonded with the $\mathrm{X}$ atoms in a trigonal prismatic arrangement $[47,48] . \mathrm{MoS}_{2}$ and $\mathrm{WS}_{2}$ are representative TMDC materials and they have a $2 \mathrm{H}$-hexagonal phase and a sizable electronic band gap, which can vary from 1.2 to $1.9 \mathrm{eV}$ and 1.34 to $2.0 \mathrm{eV}$, respectively, depending on the layer stacking number. In contrast, monolayer $\mathrm{MoTe}_{2}$ and $\mathrm{WTe}_{2}$ have a smaller band gap less than $1 \mathrm{eV}$. Especially, naturally-formed $\mathrm{WTe}_{2}$ has a distorted octahedral coordination about the tungsten atom, adopting a distorted orthorhombic phase $\left(\mathrm{Td}-\mathrm{WTe}_{2}\right)$ and the displacement of tungsten atoms with respect to those of $2 \mathrm{H}-\mathrm{WTe} \mathrm{T}_{2}$ increases the metallic bonding between tungsten atoms, creating the tungsten chains and rendering this material semimetal.

Mao et al. demonstrated that $\mathrm{MoTe}_{2} / \mathrm{WTe}_{2}$ nanosheets could serve as high-power SAs for ultrafast-pulsed laser production [49] at the wavelength of $1500 \mathrm{~nm}$. For the preparation of $\mathrm{MoTe}_{2} / \mathrm{WTe}_{2}$ nanosheets, parent $\mathrm{MoTe}_{2} / \mathrm{WTe}$ layered materials were exfoliated by an intercalation method using sodium deoxycholate bile salt (Figure 2). Compared to a micromechanical cleavage method, which is suitable for a high-quality micrometer-scale sample preparation [50], the liquid exfoliation method enabled mass production of monoto few-layered $\mathrm{MoTe}_{2} / \mathrm{WTe}_{2}$ nanosheets [51]. However, this method needs complicated processes such as mixing, sonification, centrifugation and supernatant filtering. In addition, the use of sodium deoxycholate bile salt surfactant increases the fabrication cost.

Atomic force microscopy (AFM) and transmission electron microscopy (TEM) analyses indicated that few-layered $\mathrm{MoTe}_{2} / \mathrm{WTe}_{2}$ nanosheets could be manufactured using the liquid exfoliation method (Figure 3). The $\mathrm{MoTe}_{2} / \mathrm{WTe}_{2}$ nanosheets were subsequently mixed with polyvinyl alcohol (PVA) and deposited on a side-polished to measure their saturable absorption performance. Both $\mathrm{MoTe}_{2}-\mathrm{PVA}$ and $\mathrm{WTe} \mathrm{T}_{2}-\mathrm{PVA} \mathrm{SA}$ modules showed a typical saturable absorption curve, and the modulation depth was measured as $0.9 \%$ and $1.5 \%$, respectively. In this experiment, any nonlinear response was not observed from other fiber components, indicating that the saturable absorption solely originated from $\mathrm{MoTe}_{2} / \mathrm{WTe} 2 \mathrm{SA}$ modules. 

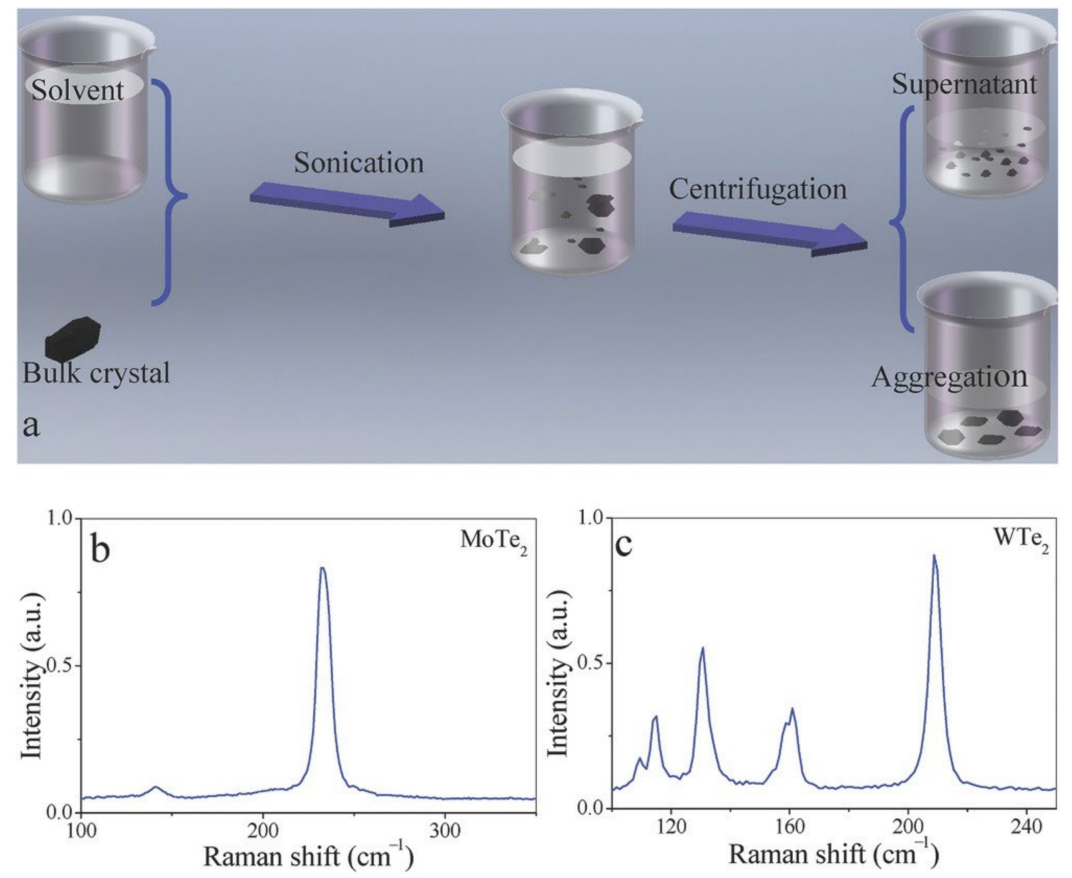

Figure 2. (a) Schematic diagram of a liquid exfoliation method for preparing $\mathrm{MoTe}_{2} / \mathrm{WTe}_{2}$ nanosheets. Raman spectra of (b) bulk $\mathrm{MoTe}_{2}$ and (c) bulk WTe 2 . Reprinted with permission from [49].
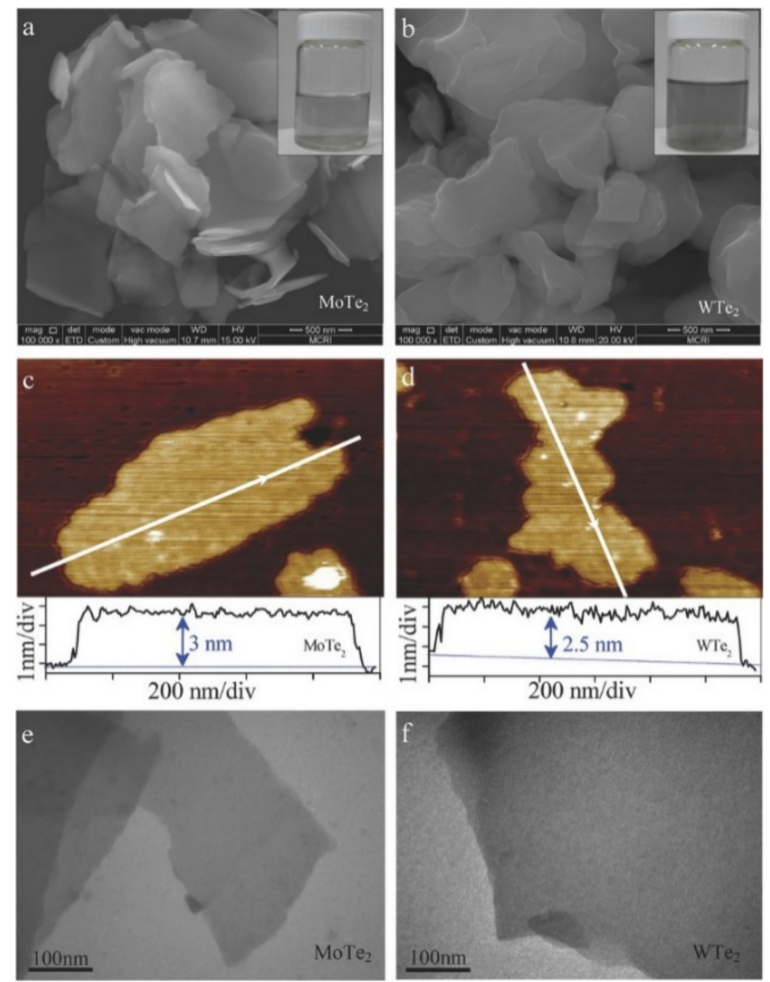

Figure 3. Characterization of $\mathrm{MoTe}_{2} / \mathrm{WTe}_{2}$ nanosheets: (a,b) SEM image; (c,d) AFM image and $(\mathbf{e}, \mathbf{f})$ TEM image. The inset shows the corresponding suspension of the nanosheets. Reprinted with permission from [49].

By using erbium-doped fiber and $\mathrm{MoTe}_{2}$ and/or $\mathrm{WTe}_{2} \mathrm{SAs}$, pulsed laser system was configurated and its performance was investigated at the wavelength of $1500 \mathrm{~nm}$. Efficient mode-locking was successfully attained using a $\mathrm{MoTe}_{2} \mathrm{SA}$, producing the ultrafast pulsed lasers with a duration of 1.2 ps. Similar outstanding performance was also observed for 
bare and/or PVA-mixed WTe 2 SAs in which mode-locking occurred at the input power of 35 and $19 \mathrm{~mW}$, respectively. Compared to other TMDCs, $\mathrm{MoTe}_{2}$ and $\mathrm{WTe}_{2}$ have greater absorption coefficients and mode-locking was induced with a lower threshold power.

Results of optical spectrum, autocorrelation trace, oscilloscopic trace and radio frequency (RF) spectrum of a WTe 2 SA-based mode-locked pulsed laser system were shown in Figure 4.
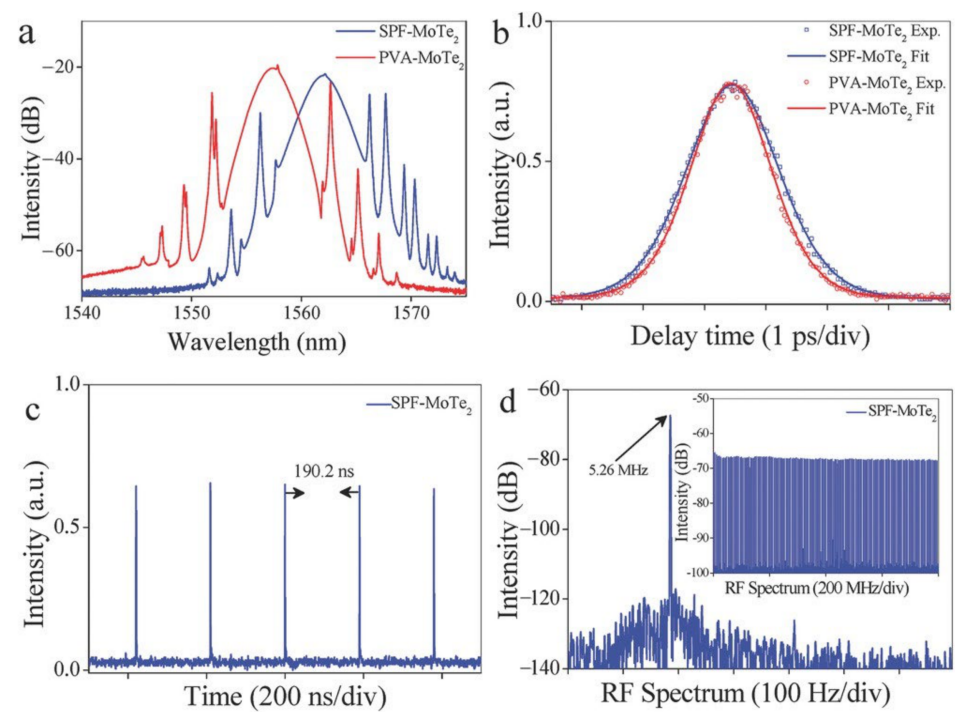

Figure 4. Results of the $\mathrm{WTe}_{2}$ mode-locked fiber lasers. (a) Spectrum, (b) autocorrelation trace, (c) pulse train and (d) RF spectrum. Reprinted with permission from [49].

\subsection{Highly Staked $\mathrm{MoTe}_{2} / \mathrm{WTe} e_{2} \mathrm{SAs}$}

Mono- and few-layer TMDCs have widely been investigated as SAs for ultrashort laser pulse generation, but their preparation is nontrivial and requires much expertise. In this regard, studies on the possible use of highly stacked TMDCs as SAs would not only be intriguing at the academic aspect, but also technically important for the development of cost-effective passively mode-locked laser technologies. Noticeably, through a combined experimental and theoretical approach, it was demonstrated that defective, highly stacked $\mathrm{WTe}_{2}$ microflakes could be superb SAs for ultrafast mode-locked pulsed lasers, enabling the production of femtosecond lasers in a fiber cavity at the wavelength of $1550 \mathrm{~nm}$ [33].

To prepare $\mathrm{WTe}_{2}$ microflakes suitable for this operation, commercial $\mathrm{WTe} \mathrm{T}_{2}$ bulk crystal was roughly disrupted by ultrasonic treatment in distilled water for consecutive $3 \mathrm{~h}$ periods with $1 \mathrm{~h}$ in-between recess. Then, the solution of $\mathrm{WTe}_{2}$ microflakes $\left(3 \mathrm{mg} \mathrm{mL}^{-1}\right)$ was taken from the top of the solution. Prior to fabrication of a SA fiber module, the solution was dropped on a glass substrate and dried for $24 \mathrm{~h}$ for structural characterization. The SEM and AFM images of the prepared $\mathrm{WTe}_{2}$ microflakes showed that the lateral dimension of the $\mathrm{WTe}_{2}$ microflakes was about $1.7 \mu \mathrm{m}$ and their thickness ranges from 80 to $150 \mathrm{~nm}$ (Figure 5). The interlayer spacing of $\mathrm{WTe}_{2}$ crystals was known as $0.75 \mathrm{~nm}$ and thus they were 100-200 stacked layers of WTe 2 . In-depth analysis showed that the $\mathrm{WTe}_{2}$ microflakes had an average overall depth of $300 \mathrm{~nm}$ (from 100 to $1000 \mathrm{~nm}$ ), being far from a monoand/or few-layered 2D material regime.

To fabricate a WTe 2 SA fiber module, the $\mathrm{WTe}_{2}$ solution was mixed with PVA and dropped on the surface of a side-polished fiber. The dimension of the $\mathrm{WTe}_{2}-\mathrm{PVA}$ film was about $10 \mathrm{~mm} \times 9 \mathrm{~mm}$ and its thickness was measured as $2.3 \mu \mathrm{m}$ using a surface profiler (DetakXP Stylus Profiler, Bruker). The optical transmission curve of the $\mathrm{WTe}_{2}-$ PVA deposited SA module was obtained using the input of a 1-ps mode-locked pulsed lasers with a wavelength of $1550 \mathrm{~nm}$ and a repetition rate of $14.15 \mathrm{MHz}$ (Figure 6). This transmission curve was fitted to following formula for quantitative SA characterization [52]. 

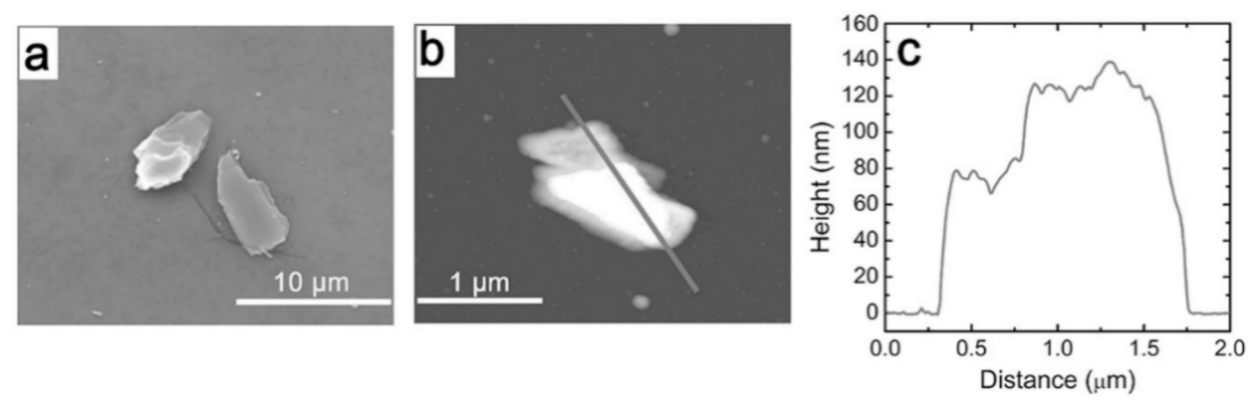

Figure 5. (a) Scanning electron microscope image and (b) atomic force microscopy image of the prepared $\mathrm{WTe}_{2}$ microflakes on a glass substrate. (c) The height profile measured along the red line in (b). Reprinted with permission from [33].

$$
T(I)=1-\Delta T \exp \left(\frac{-I}{I_{\text {sat }}}\right)-T_{\mathrm{ns}}
$$

where $T(I)$ is the transmission, $\Delta T$ is the modulation depth, $I$ is the input pulse energy, $I_{\text {sat }}$ is the saturation energy and $T_{\mathrm{ns}}$ is the non-saturable loss. The modulation depth and saturation power were measured as $2.85 \%$ and $64.6 \mathrm{~W}$, respectively. The minimum insertion loss and polarization-dependent loss of the WTe $\mathrm{W}_{2}$-PVA deposited SA module were 3.8 and $4 \mathrm{~dB}$, respectively.
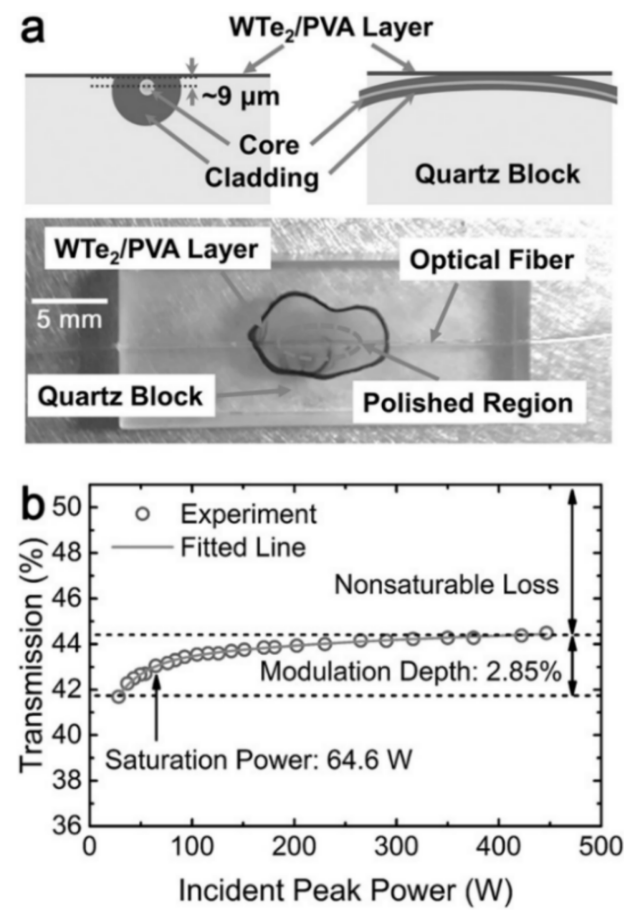

Figure 6. (a) A schematic and a photograph of the prepared side-polished fiber deposited with a $\mathrm{WTe}_{2}$-PVA composite film. (b) Measured nonlinear saturable absorption curve of the side-polished fiber deposited with a WTe 2 -PVA composite film. Reprinted with permission from [33].

$\mathrm{WTe}_{2}$ is semimetal, but it is prone to oxidation and likely to induce defects in practical applications. To gain insights to this phenomenon, density functional theory (DFT) calculations were performed for the electronic band structures of a defect-free bulk $\mathrm{WTe}_{2}$ and six monolayer $\mathrm{WTe}_{2}$ systems with different oxidation states, which had chemical compositions (Figure 7) corresponding to the experimental analysis, and the monolayer structures of $\mathrm{WTe}_{2}$ roughly stood for surface layer elements of $\mathrm{WTe}_{2}$ microflakes. 


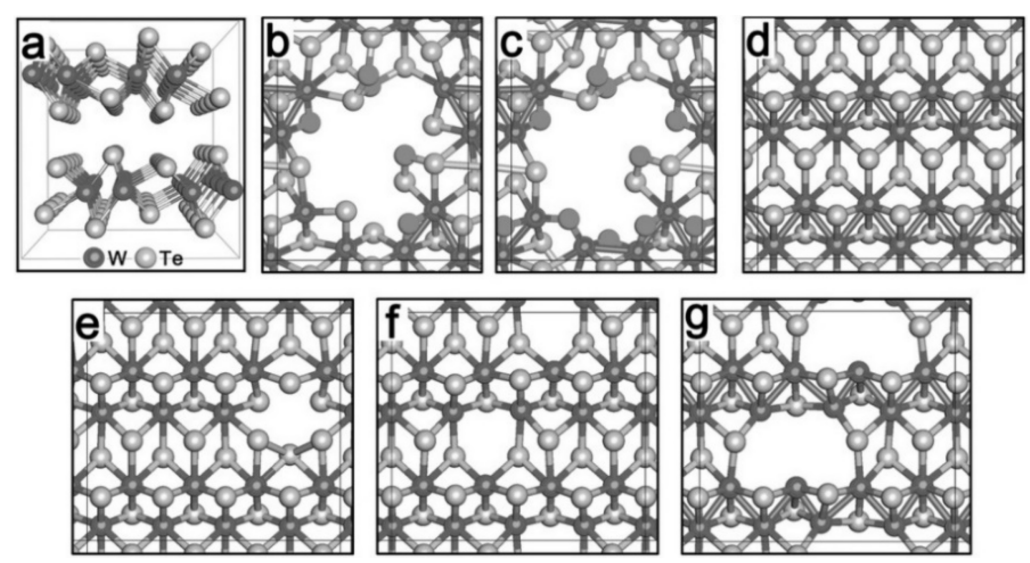

Figure 7. Atomic structures of (a) bulk $\mathrm{WTe}_{2}$, (b) $1 \mathrm{~L} \mathrm{~W}_{8} \mathrm{Te}_{18} \mathrm{O}_{5}(\mathrm{~W}: \mathrm{Te}=1: 2.25)$, (c) $1 \mathrm{~L} \mathrm{~W}_{8} \mathrm{Te}_{14} \mathrm{O}_{9}$ $(\mathrm{W}: \mathrm{Te}=1: 1.75)$, (d) $1 \mathrm{~L} \mathrm{~W}_{16} \mathrm{Te}_{32}(\mathrm{~W}: \mathrm{Te}=1: 2),(\mathbf{e}) 1 \mathrm{~L} \mathrm{~W}_{15} \mathrm{Te}_{32}(\mathrm{~W}: \mathrm{Te}=1: 2.13)$, (f) $1 \mathrm{~L} \mathrm{~W}_{16} \mathrm{Te}_{30}$ $(\mathrm{W}: \mathrm{Te}=1: 1.875)$ and $(\mathrm{g}) 1 \mathrm{~L} \mathrm{~W}_{16} \mathrm{Te}_{26}(\mathrm{~W}: \mathrm{Te}=1: 1.625)$. Tungsten, tellurium and oxygen are shown in dark two-tone gray, light-two-tone gray and dark one-tone gray, respectively. Reprinted with permission from [33].

The calculated electron band structures of these $\mathrm{WTe}_{2}$ systems were presented in Figure 8. The result for defect-free bulk $\mathrm{WTe}_{2}$ showed a good agreement with that of previous studies, validating the employed computation method $[53,54]$ Pristine monolayer $\mathrm{WTe}_{2}$ was semimetal, the same as defect-free bulk $\mathrm{WTe}_{2}$, and no energy band was observed in tungsten-deficient $\mathrm{WTe}_{2}$ (W:Te = 1:2.13). In contrast, small band gaps were observed in tellurium-deficient cases $(0.033 \mathrm{eV}$ for $\mathrm{W}: \mathrm{Te}=1: 1.875$ and 1:1.625). Meanwhile, oxidized $\mathrm{WTe}_{2}$ had rather large band gaps ranging from 0.1 to $0.2 \mathrm{eV}$. The electronic band gap should decrease upon layer stacking due to alleviated quantum confinement. [55]. Based on these facts, it was supposed that $\mathrm{WTe}_{2}$ could still operate at the near-infrared ranges $(0.9-1.7 \mathrm{eV})$ even for severe surface oxidation.
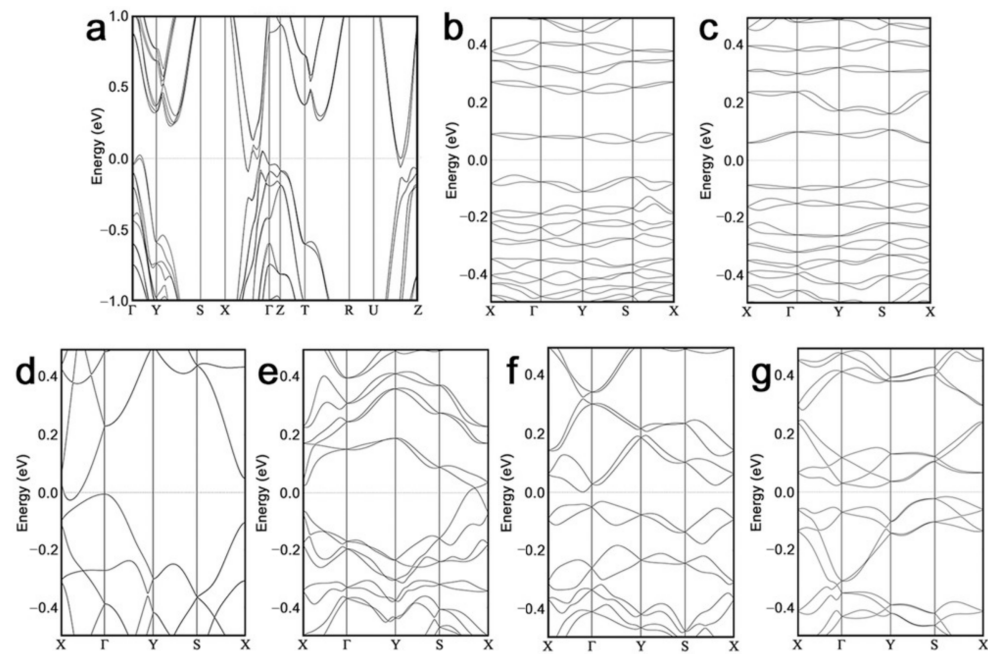

Figure 8. Electronic band structures of (a) bulk $\mathrm{WTe}_{2}$, (b) $1 \mathrm{~L} \mathrm{~W}_{8} \mathrm{Te}_{18} \mathrm{O}_{5}$ (W:Te= 1:2.25), (c) $1 \mathrm{~L}$ $\mathrm{W}_{8} \mathrm{Te}_{14} \mathrm{O}_{9}(\mathrm{~W}: \mathrm{Te}=1.75),(\mathbf{d}) 1 \mathrm{~L} \mathrm{~W}_{16} \mathrm{Te}_{32}(\mathrm{~W}: \mathrm{Te}=1: 2),(\mathbf{e}) 1 \mathrm{~L} \mathrm{~W}_{15} \mathrm{Te}_{32}(\mathrm{~W}: \mathrm{Te}=1: 2.13),(\mathbf{f}) 1 \mathrm{~L} \mathrm{~W}_{16} \mathrm{Te}_{30}$ $(\mathrm{W}: \mathrm{Te}=1: 1.875)$ and $(\mathrm{g}) 1 \mathrm{~L} \mathrm{~W}_{16} \mathrm{Te}_{26}(\mathrm{~W}: \mathrm{Te}=1: 1.625)$. Reprinted with permission from [33].

Finally, the $\mathrm{WTe}_{2} \mathrm{SA}$ module was incorporated into a ring-cavity erbium-doped fiber

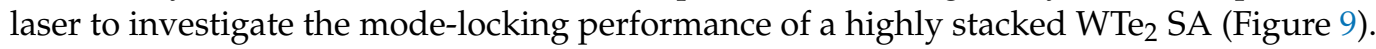
Stable mode-locked pulsed lasers were produced by increasing the pump power to $25 \mathrm{~mW}$ together with careful polarization adjustment (Figure 10a). The period and repetition rate of the generated pulses were $71.5 \mathrm{~ns}$ and $13.98 \mathrm{MHz}$, respectively, both of which agree well 
with the round-trip time and fundamental resonance frequency of the 13.69-m fiber cavity system.

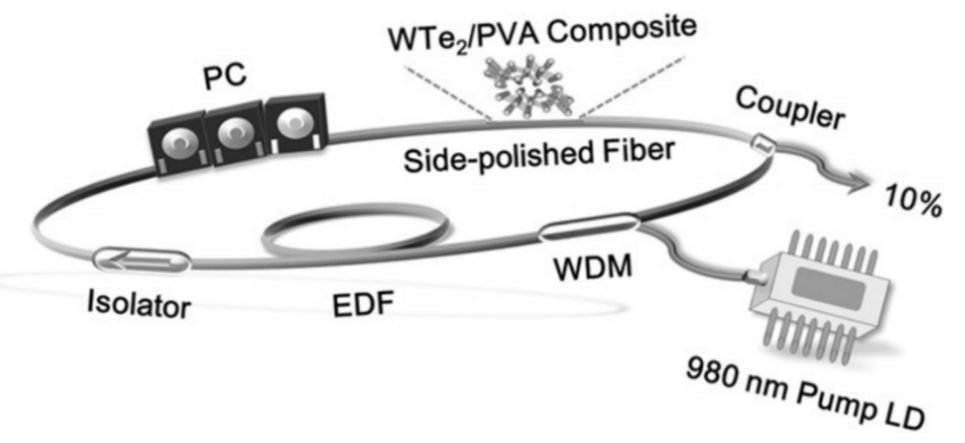

Figure 9. The schematic of the ring-cavity erbium-doped fiber laser incorporating the $\mathrm{WTe}_{2}$ microflake-based saturable absorber (SA). Here, polarization controller (PC), Er-doped fiber (EDF), wavelength division multiplexing (WDM) and laser diode (LD) denote a polarization controller, an Er-doped fiber, a wavelength division multiplexing and a laser diode, respectively. Reprinted with permission from [33].
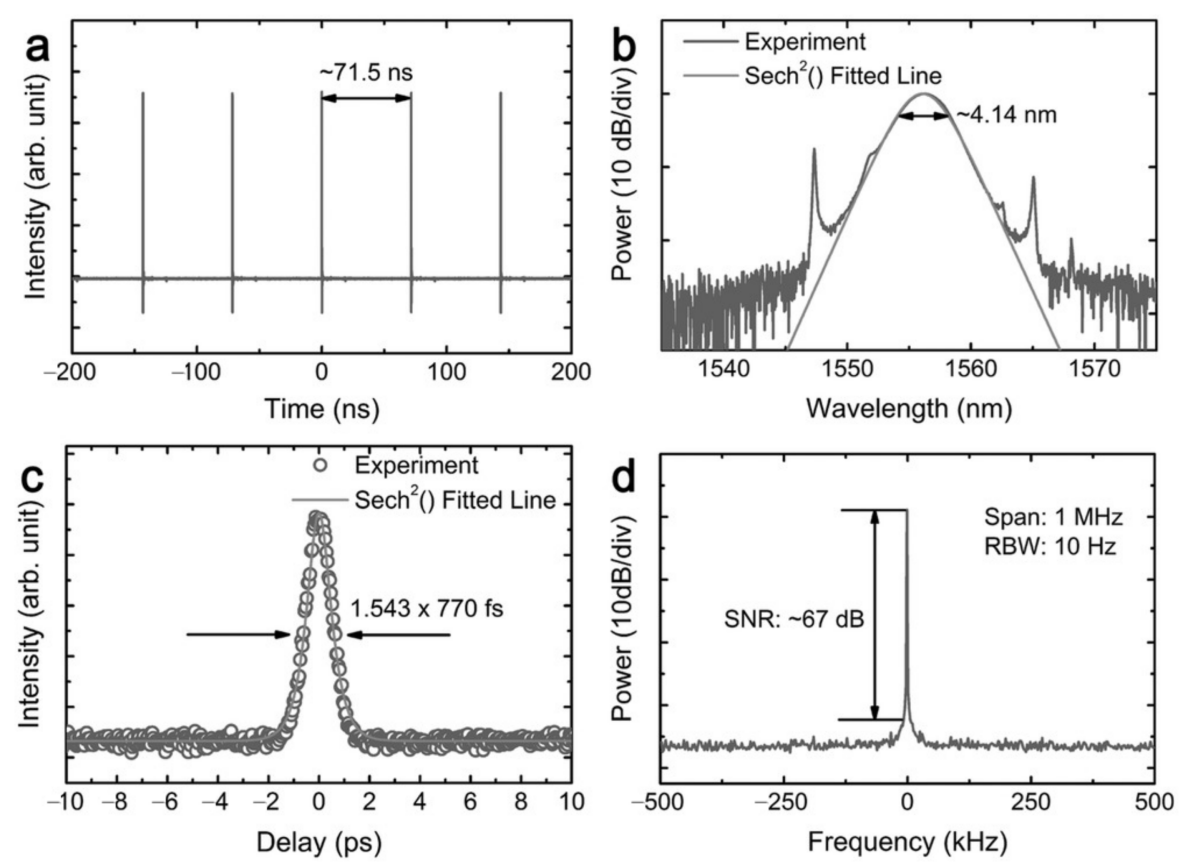

Figure 10. Measured (a) oscilloscope trace, (b) optical spectrum, (c) autocorrelation trace and (d) electrical spectrum of the output optical pulses (SNR: signal-to-noise ratio, RBW: resolution bandwidth). Reprinted with permission from [33].

The optical spectrum of the pulses is shown in Figure 10b and the sech ${ }^{2}$ fitting for solitons indicated that they have the center wavelength of $1556.2 \mathrm{~nm}$ and $3 \mathrm{~dB}$ bandwidth of $4.14 \mathrm{~nm}$. Using a two-photon absorption-based autocorrelator, the temporal width of the pulses was directly measured as $770 \mathrm{fs}$ (Figure 10c), and the time-bandwidth product was 0.39 , indicating that the output pulses were slightly chirped. In the electrical spectrum analysis, a sharp strong peak with a fundamental repetition rate of $13.98 \mathrm{MHz}$ was clearly observed with a peak-to-background ratio of $67 \mathrm{~dB}$ (Figure 10d). The SA performance of $\mathrm{WTe}_{2}$ microflakes was comparable to that of few-layered $\mathrm{WTe}_{2}$ and its mode-locking performance was even better than that of few-layered $\mathrm{WTe}_{2}$. 


\section{Topological Insulator SAs}

\subsection{Highly Stacked $B i_{2} \mathrm{Te}_{3} S A s$}

Mid-infrared laser technology has become of great research interest due to its promising potential in various emerging application fields such as mechanical processing [56], chemical detection [57], free space optical communication [58], LIDAR sensing [59,60] and laser-assisted medical diagnostics and/or surgery [61,62]. Recently, in addition to traditional mid-infrared technologies based on free-space lasers [63], considerable attention has been paid to the development of optical fiber-based mid-infrared laser systems because of their outstanding performances in terms of beam quality, compactness and reliability [64]. So far, optical fibers doped with transition metal ions such as thulium (Tm), holmium (Ho) and erbium (Er) ions have been used to make fiberized laser systems operating at the spectral region between 1.5 and $3.0 \mu \mathrm{m}$, together with an appropriate selection of host materials such as silica, silicate, tellurite and fluoride glass.

Fiber lasers can operate either in a continuous-wave or pulsed form, depending on the application purpose. For pulsed lasers, additional optical component should be implemented to induce Q-switching or mode-locking. Q-switching is achieved by modulating the quality factor (Q-factor) of the cavity in a transient mode, while mode-locking occurs by keeping the relative phases of multiple laser modes. Generally, these modulations can be achieved by two different approaches, passive and active, and SAs are the most important ingredient of passive modulation.

Recently, 2D TIs have gained huge scientific and technical attention for the development of SAs suitable for fiber lasers, particularly at the midinfrared applications, due to their prominent properties and exotic surface electronic states [65]. However, complicated processes for preparation without layer stacking had deteriorated the practical application of 2D TI-based photonic devices. If layer stacking is not a critical factor for the proper SA operation of TIs, the applicability of TIs in this field would be greatly enhanced than otherwise, and this issue has been systematically addressed as described next [66].

For this study, a side-polished fiber module deposited with highly stacked $\mathrm{Bi}_{2} \mathrm{Te}_{3} \mathrm{TIs}$ were fabricated and its nonlinear optical transmission behavior was investigated in the evanescent regime using a 1-ps mode-locked fiber pulse laser at $1950 \mathrm{~nm}$. The modulation depth of highly stacked $\mathrm{Bi}_{2} \mathrm{Te}_{3}$ TIs was as large as $20.6 \%$, while its saturation power was $29 \mathrm{~W}$. Based on this fact, passively mode-locked laser system was constructed using the highly stacked $\mathrm{Bi}_{2} \mathrm{Te}_{3} \mathrm{SA}$ fiber module (Figure 11). Specifically, the ring cavity was made using a gain medium of a 1-m long Tm/Ho co-doped fiber, an isolator, a 90:10 coupler, a polarization controller, a 1550/2000-nm wavelength division multiplexing (WDM) and a $\mathrm{Bi}_{2} \mathrm{Te}_{3}$-deposited side-polished fiber module. For input of pump beam in the ring cavity, a 1550-nm semiconductor laser diode (LD) with a maximum power of $250 \mathrm{~mW}$ was coupled with the Tm/Ho co-doped fiber using a 1550/2000 nm WDM coupler. The mode-locked laser output was extracted through a 10\% output port of a 90:10 coupler. A single-mode fiber of SM2000, which has a cut-off wavelength of $1700 \mathrm{~nm}$, is known to be more suitable to the 2000-nm operation than a standard SMF28 fiber due to a significant lower bending loss, while keeping almost similar propagation loss and dispersion as those of SMF28. Hence, in this study, all the components were fusion-spliced using the SM2000 for easy handing of system fabrication and operation, and the total length of the ring cavity was about $7 \mathrm{~m}$. The dispersion of the SM2000 and Tm/Ho codoped fiber were $-0.067 \mathrm{ps}^{2} / \mathrm{m}$ and -0.056 $\mathrm{ps}^{2} / \mathrm{m}$, respectively, at a wavelength of $1950 \mathrm{~nm}$. Based on these measurements, the total cavity dispersion was approximated as $-0.458 \mathrm{ps}^{2}$. The insertion losses of the isolator, coupler, and WDM were measured to be $1.2,0.8$ and $0.5 \mathrm{~dB}$, respectively, at $1950 \mathrm{~nm}$.

The period of the laser pulses was measured as $35.8 \mathrm{~ns}$, which corresponds to a repetition rate of $27.9 \mathrm{MHz}$, being compatible with the fundamental frequency of the ring cavity. A strong signal peak with a peak-to-background ratio of $76 \mathrm{~dB}$ was observed at the repetition rate of $27.9 \mathrm{MHz}$ in the electronic spectrum analysis. The optical spectrum measurement showed that the output pulses has a center wavelength of $1935 \mathrm{~nm}$ and a $3 \mathrm{~dB}$ bandwidth of $5.64 \mathrm{~nm}$ (Figure 12). If it is a transform-limited case, the pulse-width 
would be 698 fs. Kelly sidebands were clearly observed in the spectrum [67] in which the first-order Kelly sideband was at a distance $8.2 \mathrm{~nm}$ from the center wavelength. Using the experimentally measured total cavity dispersion value of $0.458 \mathrm{ps}^{2}$, the position of the first-order Kelly sideband was theoretically calculated as $9.117 \mathrm{~nm}$ relative to the center wavelength, assuming the transform-limited case. Figure 12b shows the theoretical plot of a relative Kelly sideband position as a function of the temporal width of transform-limited pulses for various Kelly sideband orders.

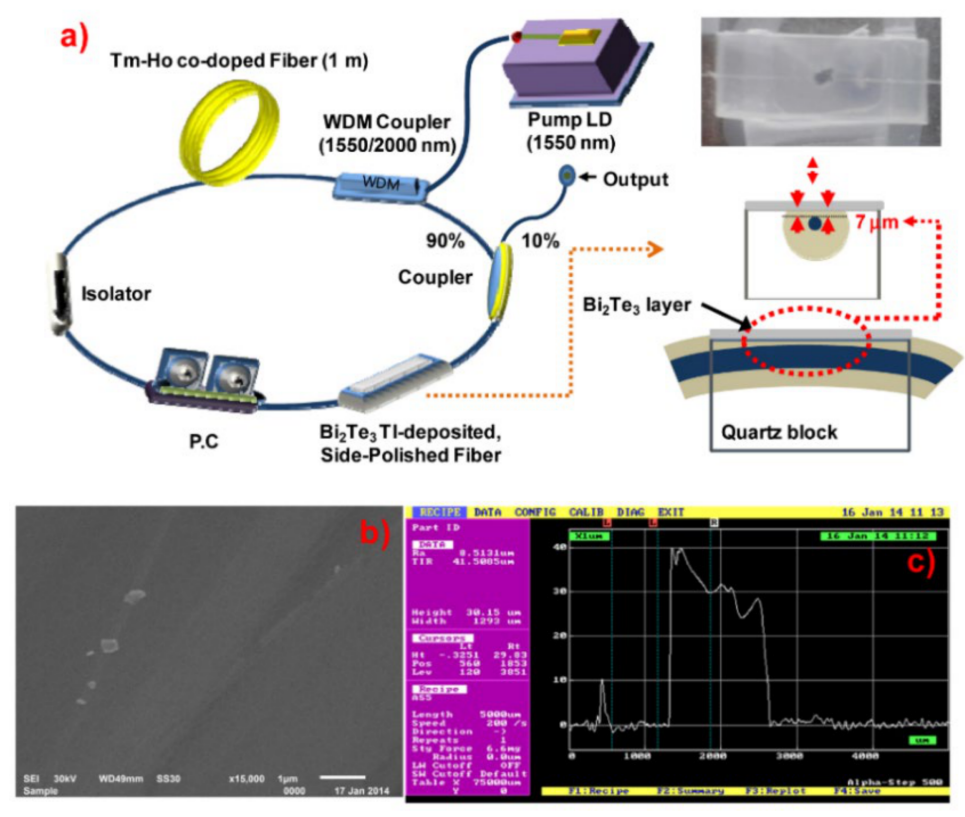

Figure 11. (a) The laser schematic. (b) Measured SEM image of the mechanically exfoliated, thick $\mathrm{Bi}_{2} \mathrm{Te}_{3}$ layer. (c) $\mathrm{Bi}_{2} \mathrm{Te}_{3}$ layer depth measurement result using an alpha step profiler. Reprinted with permission from [66].
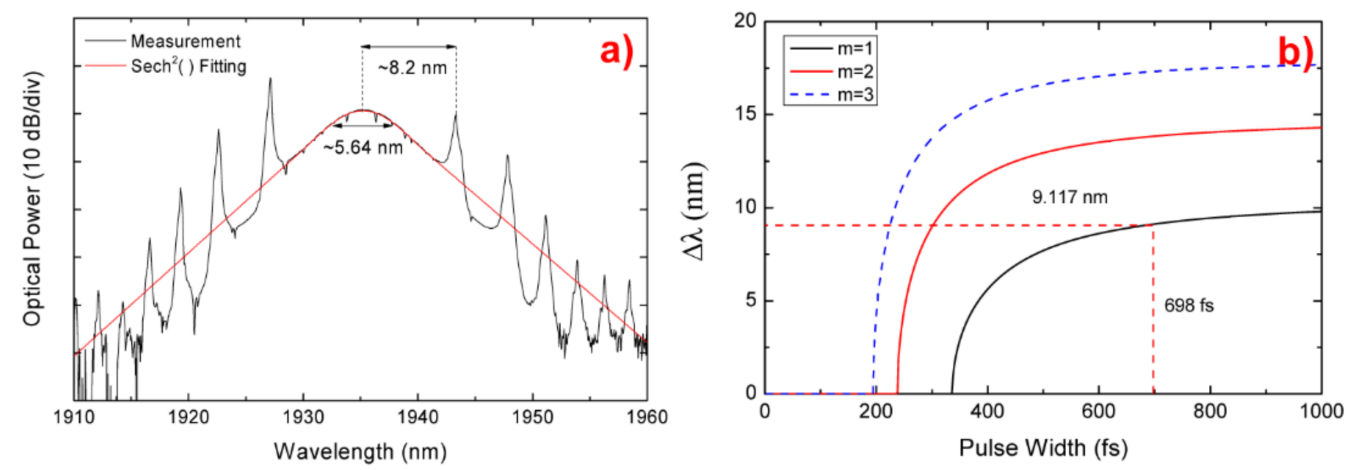

Figure 12. (a) Measured optical spectrum of output pulses. (b) Theoretically calculated Kelly sideband position relative to the center wavelength $(\Delta \lambda)$ as a function of the temporal width of transform-limited pulses for various Kelly sideband orders (m). Reprinted with permission from [66].

Small difference between experimental and theoretical values of its relative position indicates that the output pulses are slightly chirped. For a straightforward measurement of temporal width of output pulses, an autocorrelation analysis was performed using a second harmonic generation (SHG)-based autocorrelator. Since the power of the output pulses (average power of $1 \mathrm{~mW}$ ) was not high enough to induce SHG, an amplification process was taken before autocorrelation analysis. To avoid any temporal and spectral distortion of laser pulses during the amplification process, the amplification gain was carefully adjusted, attaining the average power of $20 \mathrm{~mW}$. Comparing with the original optical spectrum (Figure 12a), the amplified spectrum has almost the same spectral shape 
(Figure 13a). The autocorrelation trace showed the pulse width of $795 \mathrm{fs}$ and the time bandwidth product of 0.35 , confirming slightly chirped output pulses (Figure 13b).
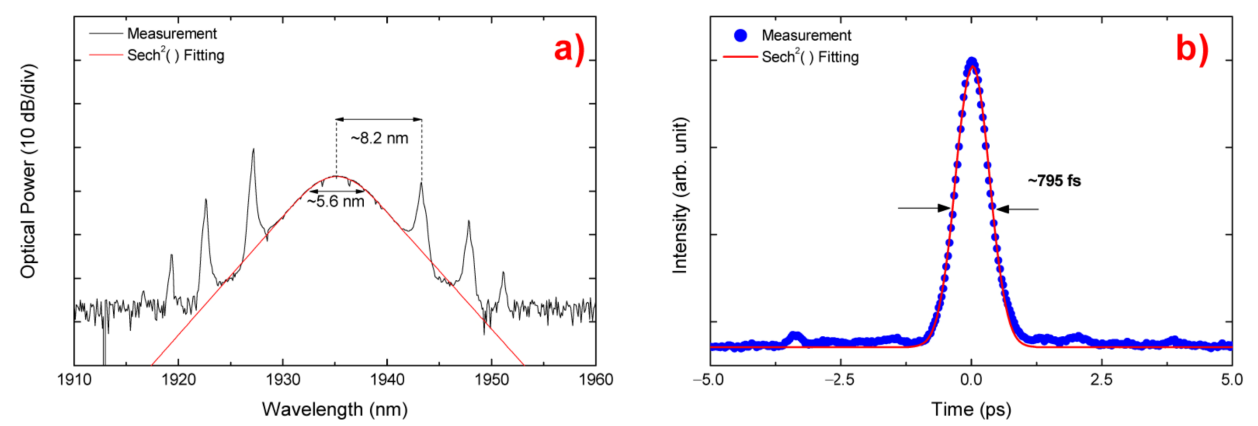

Figure 13. (a) Measured optical spectrum of amplified pulses. (b) Measured autocorrelation trace. Reprinted with permission from [66].

It should be noted that TIs have semimetal electronic band structures at the surface, being linearly dispersed across the Fermi energy level, similarly to graphene, while they have sizable band gaps at the interior region. This fact indicates the promising SA potential of TIs for the development of advanced midinfrared laser technologies, as exemplified by $\mathrm{Bi}_{2} \mathrm{Te}_{3}$.

\subsection{TI SAs for Dissipative Soliton Resonance Lasers}

Through extensive investigation on mode-locked fiber lasers performed over recent decades, it was discovered that five different types of pulses can appear in the fiber cavity via mode-locking, depending on the interplay between the Kerr effect and group velocity dispersion, which are the conventional solution [68,69], stretched pulse [70], similariton [71], dissipative soliton [72,73] and dissipative soliton resonance [74]. In a normal dispersion regime, dissipative soliton pulses with a broad temporal width can be produced through proper interaction among gain, loss, dispersion, optical nonlinearity and spectral filtering. Dissipative soliton is known to have much higher energy than conventional soliton pulses. However, even though they can generate laser pulses with a large energy, they suffered from an energy scaling issue due to pulse splitting phenomenon as the pump power become higher. Chang et al. [74] theoretically predicted that another type of mole-locked pulses, referred as dissipative soliton resonance, could also be generated under a normal dispersion condition, which was actually validated through a number of continued experiments. This laser typically produces flat-top, square-shaped pulses with a temporal width that can extend limitlessly as the pump power increases. In the dissipative soliton resonance, a pulse peak power is clamped and maintained, while its pulse energy monotonously increases as the pump power increases. Furthermore, in-depth investigation reveals that dissipative soliton resonance can occur in both the normal and anomalous dispersion spectral regions of the medium, while dissipative soliton only occurs in the normal dispersion region.

To induce the dissipative soliton resonance, various factors including saturable absorption, gain, propagation loss, Kerr effect and dispersion should be properly adjusted to obtain the desired balance. Several conditions of cavity parameters were reported for the occurrence of dissipative soliton resonance, but optimum SA parameters are yet elucidated. One obvious point is that the modulation depth should be large enough to generate the mode-locked pulses in the normal dispersion region.

Lee et al. demonstrated that pulse-width-tunable, a mode-locked fiber laser through dissipative soliton resonance could be manufactured using a highly stacked $\mathrm{Bi}_{2} \mathrm{Ti}_{3} \mathrm{TI}$ to emphasize its prominent potential in SA applications [75]. For this operation, a ringcavity fiber laser system was constructed consisting of a 6-m-long Er-doped fiber (EDF), $980 / 1550 \mathrm{~nm}$ and 1480/1550 nm WDMs, a polarization controller, an optical isolator, 1480-nm and 980-nm pump LDs, a 30:70 output coupler and most importantly a 100-m long dispersion compensating fiber (DCF) along with the incorporation of a highly stacked 
$\mathrm{Bi}_{2} \mathrm{Te}_{3} \mathrm{SA}$ module (Figure 14). Compared to normal configuration of mode-locked lasers, two points are noticeable. First, for sufficient increase of output pulse energy, two laser diodes with the wavelength of $1480 \mathrm{~nm}$ and $980 \mathrm{~nm}$ were used and their maximum pump powers were $82 \mathrm{~mW}$ and $298 \mathrm{~mW}$, respectively. Second, a 100-m long DCF with a normal dispersion of $-98 \mathrm{ps} / \mathrm{nm} \mathrm{km}$ at $1550 \mathrm{~nm}$ was employed to enhance dissipative soliton resonance while suppressing the conventional soliton evolution. The power of the 1480-nm LD was gradually increased up to the maximum amount of $298 \mathrm{~mW}$ to launch the pump power while keeping the 980-nm LD switched off, and subsequently the 980-nm LD was switched on to further increase the pump power to supply a sufficient power to the gain fiber.

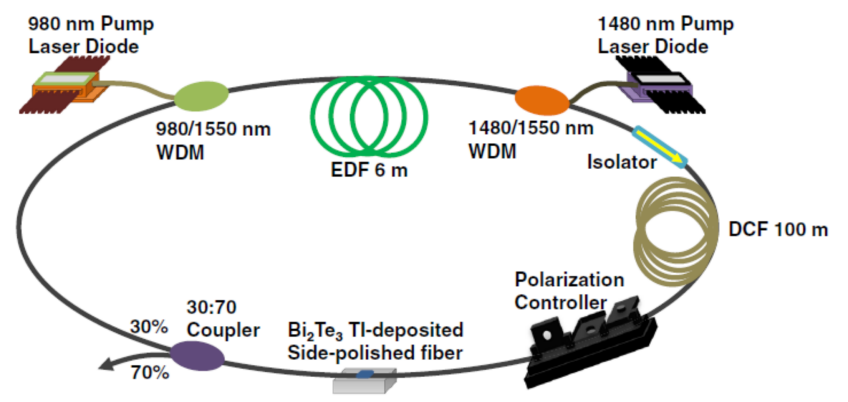

Figure 14. The fiber laser system for dissipative soliton resonance. Reprinted with permission from [75].

Conventional mode-locked pulsed lasers with a nanosecond duration were first obtained at the pump power of $88 \mathrm{~mW}$, using a 1480-nm LD only. The typical optical spectrum and oscilloscopic trace of mode-locked lasers are observed as shown in Figure 15, in which saturable absorption was dominantly responsible for passive mode-locking of the laser system. Importantly, the variation of the laser pulses was observed as further increasing the pump power and the width of the laser pulses become monotonously and continuously broadened without any pulse splitting and/or breaking, which were typical for dissipative soliton resonance (Figure 16).

The average power and peak pulse power of the output pulses were plotted as a function of the pump power, showing a well-defined linear relationship, and the output pulse energy was only limited by the lack of available pump power (Figure 17). The stability of the output pulses was guaranteed by the electronic spectrum with a significantly high signal-to-noise ratio of $51 \mathrm{~dB}$.
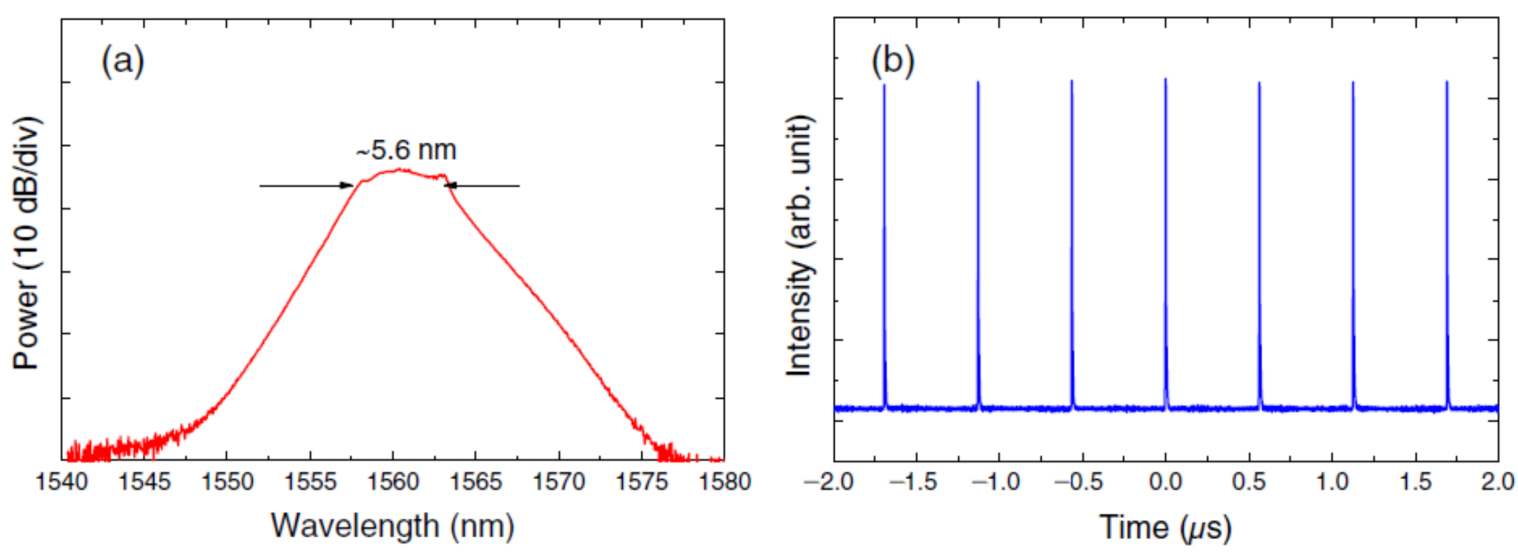

Figure 15. (a) Measured optical spectrum and (b) oscilloscope trace of the output pulses at a pump power of $88 \mathrm{~mW}$. Reprinted with permission from [75]. 

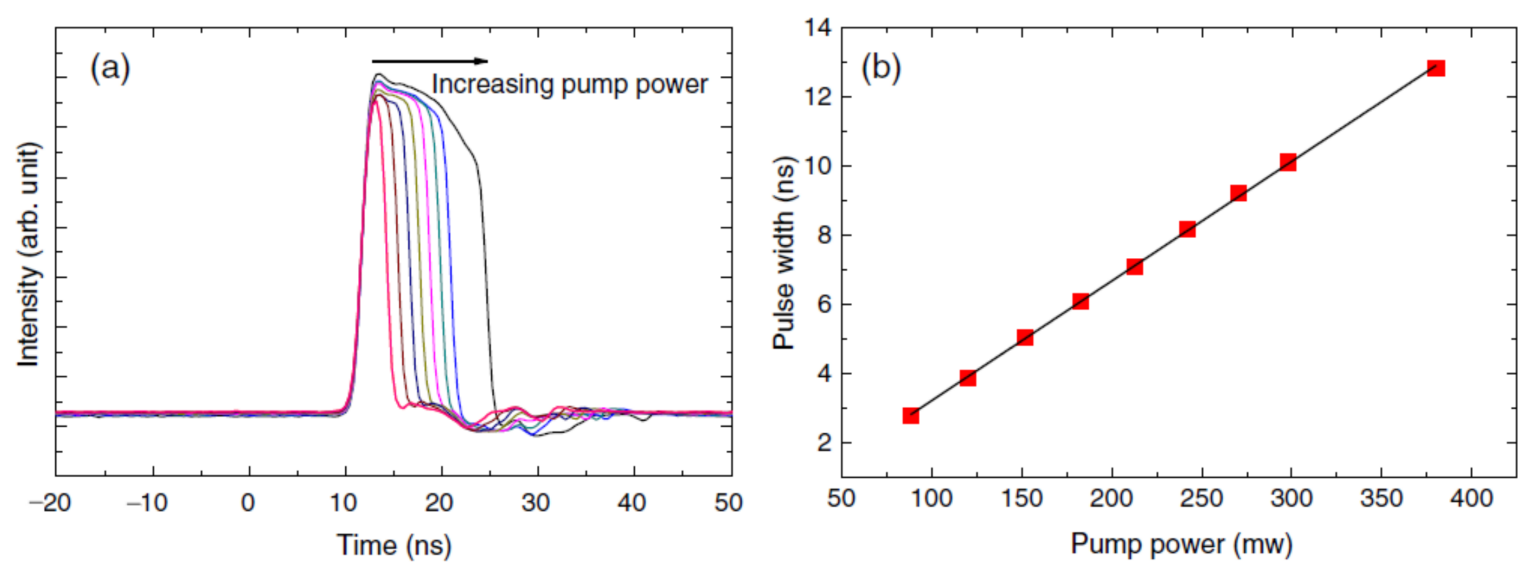

Figure 16. (a) Measured single pulses with an increasing pump power. (b) Measured output pulse width as a function of the pump power. Reprinted with permission from [75].
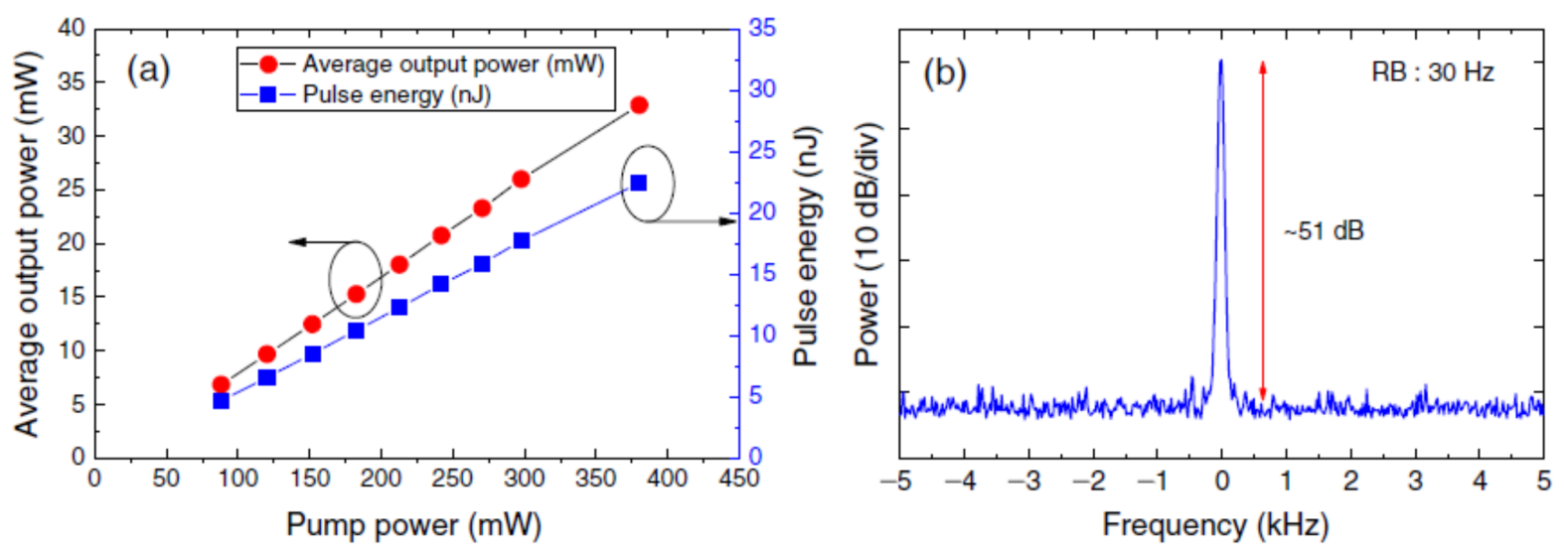

Figure 17. (a) Average output power and pulse energy measurements as a function of the pump power. (b) Measured electrical spectrum of the output pulses. Reprinted with permission from [75].

\section{Graphene and Graphite SAs}

\subsection{Graphene $S A s$}

Since the discovery in 2004, graphene, a hexagonal carbon network with monoatomic thickness, has triggered extensive studies on its various exotic physical properties. In recent years, benefiting from ultrathin nature and high light-matter interaction, graphene has attracted considerable attention from laser photonic community. Particularly, infrared laser sources in the spectral range of $1800-2000 \mathrm{~nm}$, which can be realized by fiber optical systems, are currently of topical interest due to their significance in remote sensing, spectroscopic analysis and medical therapy. This range can cover absorption lines of several important gases like carbon dioxide $\left(\mathrm{CO}_{2}\right)$ or hydrogen bromide $(\mathrm{HBr})$ [76], suggesting possible construction of cost-effective high-performance gas sensing platforms. It has also been shown that 2000-nm laser outperform 1000-nm and 1550-nm sources for dermatological treatment and medical surgery, allowing precise and efficient optical scalpels [77,78].

Sobon et al. used graphene as a SA to make 1884-nm pulsed laser via efficient passive mode-locking by simply inserting graphene between the ferrule connectors of a fiber cavity [79]. For large-area production, a graphene film was fabricated by a chemical vapor deposition method and carefully transferred onto the ferrule of a ring-fiber cavity incorporated with a Tm-doped gain fiber suitable for 1900-nm laser production (Figure 18). To confirm that the mode-locking originates from the graphene SA, the laser was first launched without a deposited graphene SA and mode-locking did not occur for any configuration of a polarization controller (PC). Then, the graphene SA was incorporated into the laser system in a transmission mode, not in an evanescent mode that allows for 
more feasible mode-locking. Despite this, the system has readily produced well-defined mode-locked pulses as shown in Figure 19. Characteristic dips in the high-resolution spectrum were proven to coincide with water absorption lines. The optical spectral shape without these dips exhibited well the soliton features. It was supposed that the ultrathin nature of 2D materials could contribute to optical loss control/reduction and interfacial fitness for better mode-locking of SAs in a transmission mode.

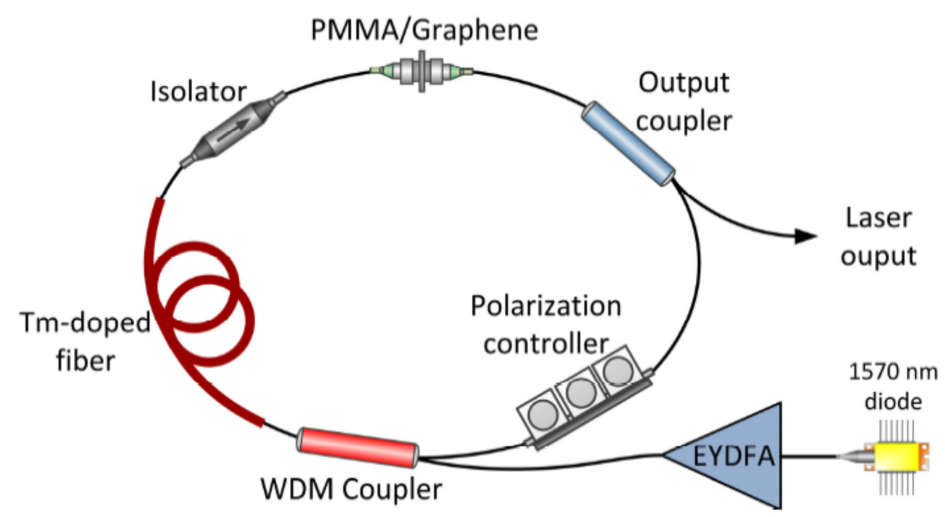

Figure 18. Tm-doped fiber laser system incorporated with a sandwiched graphene SA module. Reprinted with permission from [79].
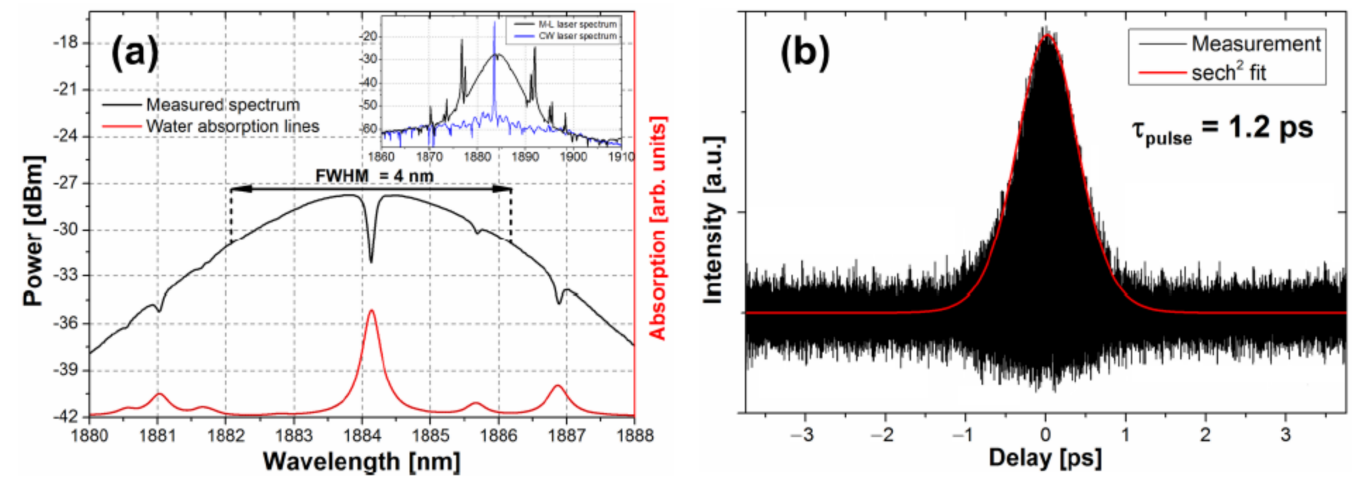

Figure 19. (a) Measured optical spectrum and (b) autocorrelation trace of the laser system. Reprinted with permission from [79].

\subsection{Graphite $S A s$}

To investigate the potential of highly stacked graphene in saturable absorption applications, graphite in a pencil was incorporated into a 1550-nm fiber laser system by simple sketching onto ferrule connectors in the fiber ring cavity [80], which would be a stringent case of highly stacked graphene. Despite its rawness, this system produced well-defined Q-switched pulsed lasers. The details of the laser system are shown in Figure 20. A 3-m long EDF, which exhibited almost complete absorption (30 dB) of 980-nm pump beam, was used as a gain medium, and a LD with a maximum power of $273 \mathrm{~mW}$ was used as a pump source. The LD was coupled with the gain fiber through a 980/1550 nm WDM and for unidirectional light, an isolator was placed between a WDM and a graphite SA.

When the pump power reached $169 \mathrm{~mW}$, Q-switched pulsed lasers were produced in the ring cavity. The Q-switched pulses maintained up to the maximum pump power of $273 \mathrm{~mW}$ with good stability. The oscilloscope traces of the output pulses showed the typical pump power-dependent features of Q-switching (Figure 21a). The repetition rate increased from 39.86 to $46.08 \mathrm{kHz}$ as the pump power increased, whereas the pulse width decreased from 2.71 to $1.98 \mu \mathrm{s}$. The optical spectrum measured at the pump power of $273 \mathrm{~mW}$ indicated that the center wavelength and $3 \mathrm{~dB}$ bandwidth of laser pulses were $1559.3 \mathrm{~nm}$ and $2.5 \mathrm{~nm}$, respectively (Figure $21 \mathrm{~b}$ ). The average energy and peak energy of 
the output laser pulses monotonically increased as the pump power increased. The system used a very thick raw state of graphite and further improvement of performance would be possible through structure refinement and system optimization, which was actually achieved by continued studies [81].

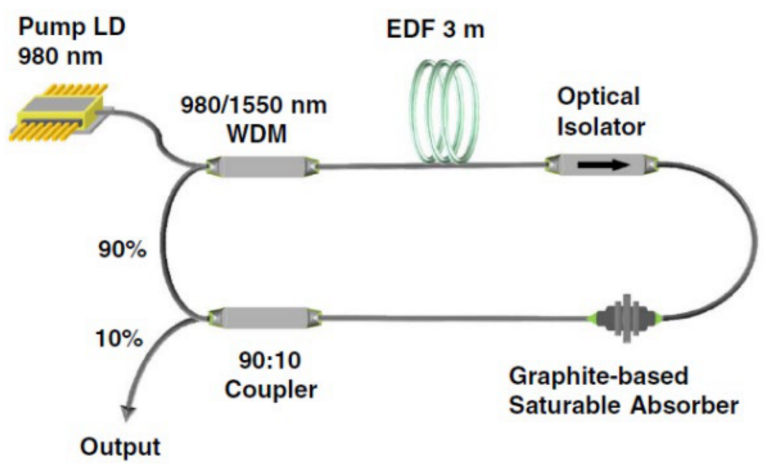

Figure 20. The configuration of a Q-switched fiber laser using a pencil graphite SA. Reprinted with permission from [80].
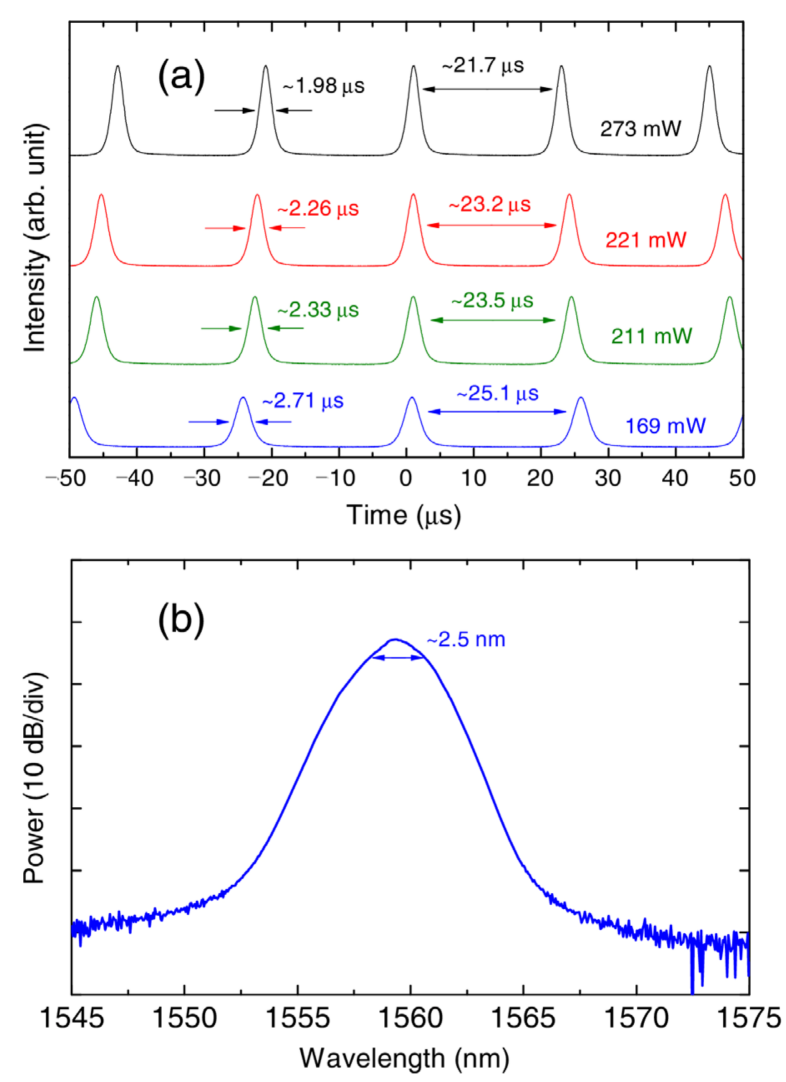

Figure 21. (a) Oscilloscope traces of output pulses measured at various pump powers. (b) Optical spectrum of output pulses obtained at a pump power of $273 \mathrm{~mW}$. Reprinted with permission from [80].

\section{Perspective of 2D Material SAs}

Through extensive researches, it was observed that the mode-locking performance of 2D material SAs was seldom deteriorated by significant layer stacking as summarized in Table 1 including studies introduced in this review. We see that femtosecond pulsed lasers can be readily produced by high-stacked $2 \mathrm{D}$ material SAs. 
Table 1. Output performance comparison of mode-locked fiber lasers using highly stacked 2D material SAs and others.

\begin{tabular}{|c|c|c|c|c|c|c|}
\hline $\begin{array}{l}\text { Saturable } \\
\text { Absorber }\end{array}$ & Fiber Platform & Wave Length (nm) & $\begin{array}{l}\text { Modulation } \\
\text { Depth (\%) }\end{array}$ & Saturation Level & Pulse Width (fs) & Refs \\
\hline Few Layered $\mathrm{WTe}_{2}$ & Side-Polished Fiber & 1561 & 2.8 & NA & 1200 & [49] \\
\hline Bulk Structured WTe ${ }_{2}$ & Side-Polished Fiber & 1556.2 & NA & $59 \mathrm{MW} / \mathrm{cm}^{2}$ & 770 & [33] \\
\hline Nanostructured $\mathrm{Bi}_{2} \mathrm{Te}_{3}$ & Tapered Fiber & 1909.5 & 9.8 & NA & 1260 & {$[82]$} \\
\hline Bulk Structured $\mathrm{Bi}_{2} \mathrm{Te}_{3}$ & Side-Polished Fiber & 1935 & 20.6 & $29 \mathrm{~W}$ & 795 & {$[66]$} \\
\hline Graphene & Fiber Ferrule & 1884 & NA & NA & 1200 & [79] \\
\hline Graphene & Fiber Ferrule & 1555 & 3.6 & 0.08 & 590 & {$[34]$} \\
\hline Graphite & Fiber Ferrule & 1563 & 21 & NA & 472 & [81] \\
\hline
\end{tabular}

NA: Not Available. Saturation level units of $\mathrm{W}$ and $\mathrm{MW} / \mathrm{cm}^{2}$ are for saturation power and saturation intensity, respectively.

Apart from sandwiched and/or side-polished fiber modules, SAs can also be incorporated into tapering fiber modules in which coating is etched radially around the fiber and SAs are deposited all around the etched fiber. Highly stacked SAs still showed excellent modulation performance in this type of SA modules [83]. In this review, we only introduced the progresses of 2D material SAs achieved in the spectral range of fiber photonics. However, using 2D materials with appropriate electronic and optical properties, the application range can be further extended to other spectral regions such as visible and terahertz ones [84,85]. Visible orange-light laser pulses were readily produced using a WS ${ }_{2}$-coated mirror and a $\mathrm{Pr}^{3+}$-doped ZBLAN $\left(\mathrm{ZrF}_{4}-\mathrm{BaF}_{2}-\mathrm{LaF}_{3}-\mathrm{AlF}_{3}-\mathrm{NaF}\right)$ fiber gain medium (core/cladding: 6/125 $\mu \mathrm{m}$, numerical aperture (NA) of $0.15, \mathrm{Pr}^{3+}$ concentration of 1000), suggesting a possible broadband application of 2D material SAs [84].

The setup for this free-space pulsed laser is shown in Figure 22. When a $\mathrm{WS}_{2} \mathrm{SA}$ was not used in the system, it generated orange-light continuous wave lasers. However, when $\mathrm{WS}_{2}$ mirrors were incorporated into the laser system, it produced orange-light Q-switched lasers whose typical oscilloscopic traces were clearly observed for various input powers (Figure 23).
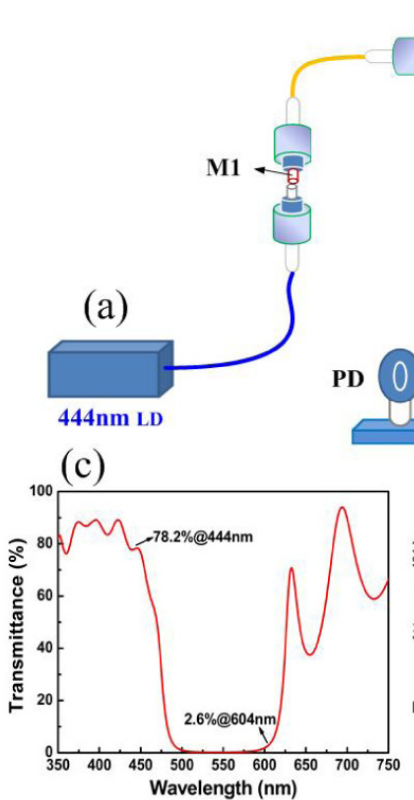
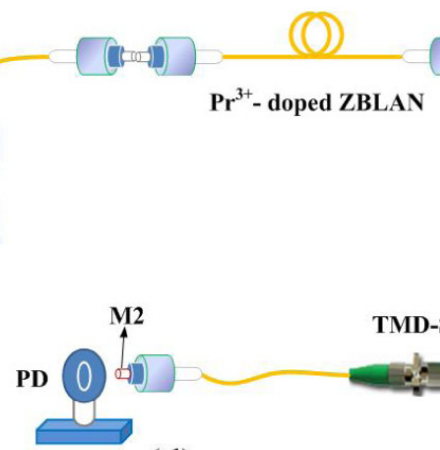

(d)
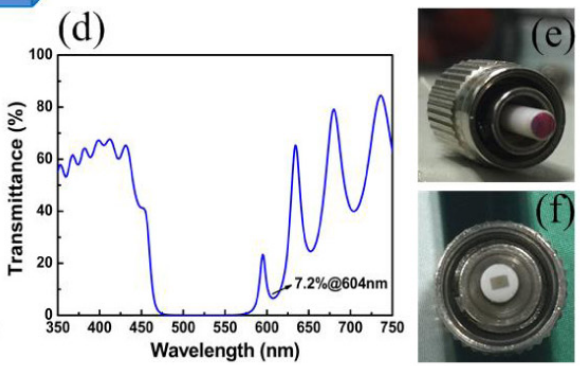

(b)

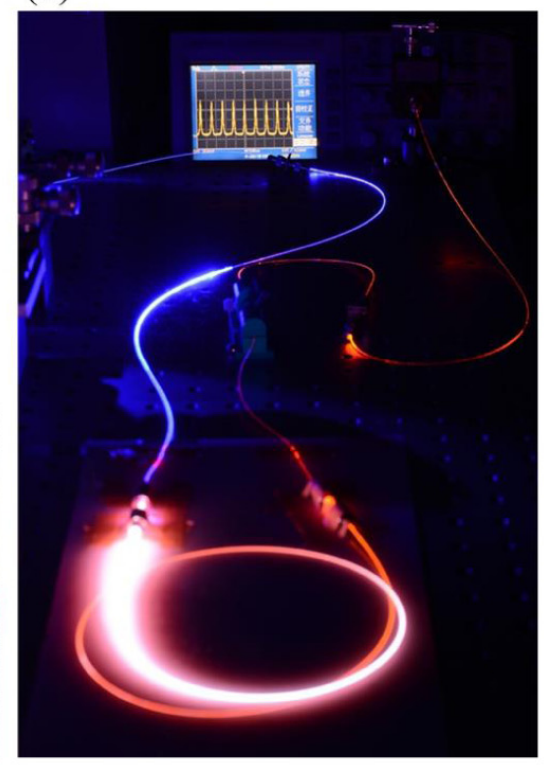

Figure 22. (a) Schematic illustration and (b) experimental picture of compact transition metal dichalcogenides (TMDCs)based passively Q-switched orange-light $\mathrm{Pr}^{3+}$-doped all-fiber laser. Transmission spectrum of the fiber pigtail mirrors (FPMs): (c) input mirror M1 and (d) output mirror M2. (e) An image of the FPM, and (f) a photograph of the fiber-end coated by a TMDC film. Reprinted with permission from [84]. 

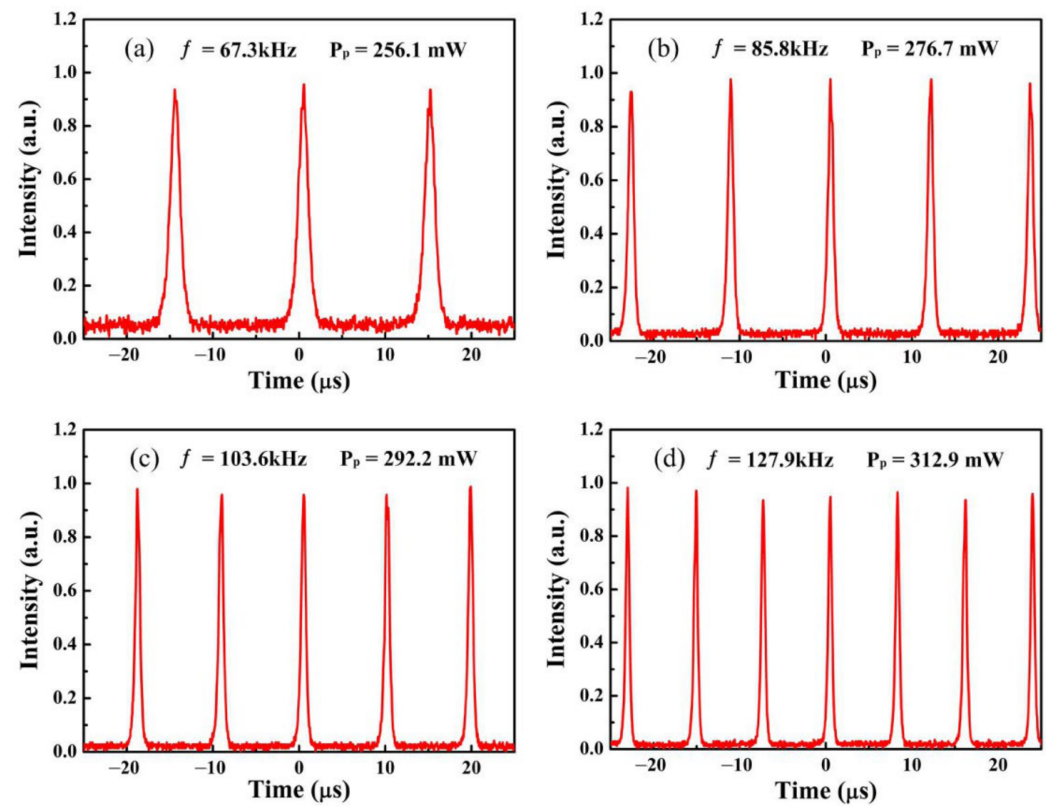

Figure 23. Passive Q-switching pulse trains of orange-light $\mathrm{Pr}^{3+}$-doped all-fiber laser based on $\mathrm{WS}_{2}$ SA under different incident pump powers of $\mathrm{P}_{\mathrm{p}}$. (a) $\mathrm{P}_{\mathrm{p}}=256.1 \mathrm{~mW}$, (b) $\mathrm{P}_{\mathrm{p}}=276.7 \mathrm{~mW}$, (c) $\mathrm{P}_{\mathrm{p}}=292.2 \mathrm{~mW}$ and (d) $\mathrm{P}_{\mathrm{p}}=312.9 \mathrm{~mW}$. Reprinted with permission from [84].

Although highly stacked 2D material SAs can have a fairly good modulation performance in laser photonics, mono- and/or few-layer 2D material SAs would have their own merits as it could be more desirable for transmission-mode applications such as sandwiched-type SA modules in fiber laser systems and/or SA coated mirrors in free space lasers. Despite the promising potential of SAs in modern photonic technologies, the development direction of 2D material SAs is not elucidated and remains rather ambiguous. Regarding this, the research experience indicated the tendency that good 2D material SAs generally possess high thermoelectric properties and that good thermoelectric operation is beneficial for saturable absorption. It is noteworthy that key ingredients of thermoelectric materials and TIs are very similar to each other. In summary, 2D material SAs can provide a rich platform for advanced pulsed laser technologies allowing superb optical switching and passive mode-locking in the broadband spectral range. Continued studies on these 2D material SAs will significantly contribute to the development of novel types of high-performance photonic devices in the future.

Author Contributions: Conceptualization, Y.I.J. and J.H.L.; methodology, Y.I.J. and J.H.L.; validation, Y.I.J. and J.H.L.; formal analysis, Y.I.J. and J.H.L.; investigation, Y.I.J. and J.H.L.; resources, Y.I.J. and J.H.L.; data curation, Y.I.J. and J.H.L.; writing-original draft preparation, Y.I.J.; writing-review and editing, Y.I.J. and J.H.L.; visualization, Y.I.J.; supervision, J.H.L.; project administration, Y.I.J.; funding acquisition, Y.I.J. All authors have read and agreed to the published version of the manuscript.

Funding: This research was funded by by Basic Science Research Program through the National Research Foundation of Korea funded by the Ministry of Education (2019R1I1A1A01060876).

Institutional Review Board Statement: Not applicable.

Informed Consent Statement: Not applicable.

Data Availability Statement: Not applicable.

Conflicts of Interest: The authors declare no conflict of interest.

\section{References}

1. Boyd, R.W. Nonlinear Optics, 3rd ed.; Academic Press: Cambridge, MA, USA, 2008.

2. Franken, P.A.; Hill, A.E.; Peters, C.W.; Weinreich, G. Generation of optical harmonics. Phys. Rev. Lett. 1961, 7, 118-119. [CrossRef] 
3. Kerr, J. XL. A new relation between electricity and light: Dielectrified media birefringent. Lond. Edinb. Dubl. Philos. Mag. J. Sci. 1875, 50, 337-348. [CrossRef]

4. Bass, M.; Franken, P.A.; Ward, J.F.; Weinreich, G. Optical rectification. Phys. Rev. Lett. 1962, 9, 446-448. [CrossRef]

5. Colin, S.; Contesse, E.; Le Boudec, P.; Stephan, G.; Sanchez, F. Evidence of a saturable-absorption effect in heavily erbium-doped fibers. Opt. Lett. 1996, 21, 1987-1989. [CrossRef] [PubMed]

6. Keller, U. Recent developments in compact ultrafast lasers. Nature 2003, 424, 831-838. [CrossRef] [PubMed]

7. Jiang, T.; Xu, Y.; Tian, Q.; Liu, L.; Kang, Z.; Yang, R.; Qin, G.; Qin, W. Passively Q-switching induced by gold nanocrystals. Appl. Phys. Lett. 2012, 101, 151122. [CrossRef]

8. Weigand, R.; Balmaseda, M.; Pérez, J. Q-switched operation with carbon-based saturable absorbers in a Nd:YLF Laser. Appl. Sci. 2015, 5, 566-574. [CrossRef]

9. Jhon, Y.I.; Kim, C.; Seo, M.; Cho, W.J.; Lee, S.; Jhon, Y.M. Tensile characterization of single-walled carbon nanotubes with helical structural defects. Sci. Rep. 2016, 6, 20324. [CrossRef] [PubMed]

10. Wang, J.; Hernandez, Y.; Lotya, M.; Coleman, J.N.; Blau, W.J. Broadband nonlinear optical response of graphene dispersions. Adv. Mater. 2009, 21, 2430-2435. [CrossRef]

11. Qiao, J.; Sung, W.H.; Lan, J.C.; Lin, Y.Y.; Wu, M.Y.; Fan, R.; Li, Y.; Qiao, W.; Liu, H.; Zhao, S.; et al. Are graphene-Bi2Te3van der Waals heterostructure-based saturable absorbers promising for solid-state Q-switched lasers? Opt. Lett. 2019, 44, 1072. [CrossRef]

12. Choi, W.; Choudhary, N.; Han, G.H.; Park, J.; Akinwande, D.; Lee, Y.H. Recent development of two-dimensional transition metal dichalcogenides and their applications. Mater. Today 2017, 20, 116-130. [CrossRef]

13. Kou, L.; Ma, Y.; Sun, Z.; Heine, T.; Chen, C. Two-dimensional topological insulators: Progress and prospects. J. Phys. Chem. Lett. 2017, 8, 1905-1919. [CrossRef]

14. Liu, H.; Neal, A.T.; Zhu, Z.; Luo, Z.; Xu, X.; Tománek, D.; Ye, P.D. Phosphorene: An unexplored 2D semiconductor with a high hole mobility. ACS Nano 2014, 8, 4033-4041. [CrossRef] [PubMed]

15. Anasori, B.; Lukatskaya, M.R.; Gogotsi, Y. 2D metal carbides and nitrides (MXenes) for energy storage. Nat. Rev. Mater. 2017, 2, 16098. [CrossRef]

16. Jhon, Y.I.; Seo, M.; Jhon, Y.M. First-principles study of a MXene terahertz detector. Nanoscale 2018, 10, 69-75. [CrossRef]

17. Jhon, Y.I.; Jhon, Y.M.; Lee, J.H. Nonlinear optics of MXene in laser technologies. J. Phys. Mater. 2020, 3, 032004. [CrossRef]

18. Jhon, Y.I.; Jhon, Y.M.; Lee, J.H. Broadband ultrafast photonics of two-dimensional transition metal carbides (MXenes). Nano Futures 2020, 4, 032003. [CrossRef]

19. Li, Y.; Dong, N.; Zhang, S.; Zhang, X.; Feng, Y.; Wang, K.; Zhang, L.; Wang, J. Giant two-photon absorption in monolayer MoS2. Laser Photonics Rev. 2015, 9, 427-434. [CrossRef]

20. Lin, Y.Y.; Song, W.H.; Lee, P.; Wang, Y.R.; Zhang, H.; Lee, C.K. Dynamic cavity effects in topological insulator Bi2Te3 based passive Q-switched solid state laser. J. Phys. Commun. 2018, 2, 125007. [CrossRef]

21. Jhon, Y.I.; Zhu, S.E.; Ahn, J.H.; Jhon, M.S. The mechanical responses of tilted and non-tilted grain boundaries in graphene. Carbon 2012, 50, 3708-3716. [CrossRef]

22. Jhon, Y.I.; Jhon, Y.M.; Yeom, G.Y.; Jhon, M.S. Orientation dependence of the fracture behavior of graphene. Carbon 2014, 66, 619-628. [CrossRef]

23. Lee, C.; Wei, X.; Kysar, J.W.; Hone, J. Measurement of the Elastic Properties and Intrinsic Strength of Monolayer Graphene. Science 2008, 321, 385-388. [CrossRef]

24. Cohen-Tanugi, D.; Grossman, J.C. Water Desalination across Nanoporous Graphene. Nano Lett. 2012, 12, 3602-3608. [CrossRef]

25. Jhon, Y.I.; Kim, C.; Byun, Y.T.; Lee, J.H.; Jhon, Y.M. Facile large-area fabrication of highly selective and permeable few-layered graphene: A molecular dynamics study. Carbon 2019, 155, 369-378. [CrossRef]

26. Kim, Y.; Jhon, Y.I.; Park, J.; Kim, C.; Lee, S.; Jhon, Y.M. Plasma functionalization for cyclic transition between neutral and charged excitons in monolayer $\mathrm{MoS}_{2}$. Sci. Rep. 2016, 6, 21405. [CrossRef] [PubMed]

27. Jhon, Y.I.; Kim, Y.; Park, J.; Kim, J.H.; Lee, T.; Seo, M.; Jhon, Y.M. Significant exciton brightening in monolayer tungsten disulfides via fluorination: N-type gas sensing semiconductors. Adv. Funct. Mater. 2016, 26, 7551-7559. [CrossRef]

28. Chaves, A.; Azadani, J.G.; Alsalman, H.; da Costa, D.R.; Frisenda, R.; Chaves, A.J.; Song, S.H.; Kim, Y.D.; He, D.; Zhou, J.; et al. Bandgap engineering of two-dimensional semiconductor materials. Npj 2D Mater. Appl. 2020, 4, 29. [CrossRef]

29. Jhon, Y.I.; Koo, J.; Anasori, B.; Seo, M.; Lee, J.H.; Gogotsi, Y.; Jhon, Y.M. Metallic MXene saturable absorber for femtosecond mode-locked lasers. Adv. Mater. 2017, 29, 1702496. [CrossRef]

30. Liu, H.; Zheng, X.W.; Liu, M.; Zhao, N.; Luo, A.P.; Luo, Z.C.; Xu, W.C.; Zhang, H.; Zhao, C.J.; Wen, S.C. Femtosecond pulse generation from a topological insulator mode-locked fiber laser. Opt. Express 2014, 22, 6868. [CrossRef]

31. Jhon, Y.I.; Lee, J.; Jhon, Y.M.; Lee, J.H. Topological insulators for mode-locking of 2- $\mu \mathrm{m}$ fiber lasers. IEEE J. Sel. Top. Quantum Electron. 2018, 24, 110220. [CrossRef]

32. Jhon, Y.I.; Lee, J.; Seo, M.; Lee, J.H.; Jhon, Y.M. Van der Waals layered tin selenide as highly nonlinear ultrafast saturable absorber. Adv. Opt. Mater. 2019, 7, 1801745. [CrossRef]

33. Koo, J.; Jhon, Y.I.; Park, J.; Lee, J.; Jhon, Y.M.; Lee, J.H. Near-infrared saturable absorption of defective Bulk-structured Wte2for femtosecond laser mode-locking. Adv. Funct. Mater. 2016, 26, 7454-7461. [CrossRef]

34. Sobon, G.; Sotor, J.; Abramski, K.M. All-polarization maintaining femtosecond Er-doped fiber laser mode-locked by graphene saturable absorber. Laser Phys. Lett. 2012, 9, 581-586. [CrossRef] 
35. Lee, J.; Koo, J.; Debnath, P.; Song, Y.W.; Lee, J.H. AQ-switched, mode-locked fiber laser using a graphene oxide-based polarization sensitive saturable absorber. Laser Phys. Lett. 2013, 10, 035103. [CrossRef]

36. Boguslawski, J.; Sotor, J.; Sobon, G.; Tarka, J.; Jagiello, J.; Macherzynski, W.; Lipinska, L.; Abramski, K.M. Mode-locked Er-doped fiber laser based on liquid phase exfoliated $\mathrm{Sb}_{2} \mathrm{Te}_{3}$ topological insulator. Laser Phys. 2014, 24, 105111. [CrossRef]

37. Chen, Y.; Jiang, G.; Chen, S.; Guo, Z.; Yu, X.; Zhao, C.; Zhang, H.; Bao, Q.; Wen, S.; Tang, D.; et al. Mechanically exfoliated black phosphorus as a new saturable absorber for both Q-switching and mode-locking laser operation. Opt. Express 2015, $23,12823$. [CrossRef]

38. Liu, H.; Luo, A.P.; Wang, F.Z.; Tang, R.; Liu, M.; Luo, Z.C.; Xu, W.C.; Zhao, C.J.; Zhang, H. Femtosecond pulse erbium-doped fiber laser by a few-layer $\mathrm{MoS}_{2}$ saturable absorber. Opt. Lett. 2014, 39, 4591. [CrossRef]

39. Li, Z.; Pang, C.; Li, R.; Chen, F. Low-dimensional materials as saturable absorbers for pulsed waveguide lasers. J. Phys. Photon. 2020, 2, 031001. [CrossRef]

40. Wu, K.; Zhang, X.; Wang, J.; Li, X.; Chen, J. WS 2 as a saturable absorber for ultrafast photonic applications of mode-locked and Q-switched lasers. Opt. Express 2015, 23, 11453. [CrossRef] [PubMed]

41. Mao, D.; Wang, Y.; Ma, C.; Han, L.; Jiang, B.; Gan, X.; Hua, S.; Zhang, W.; Mei, T.; Zhao, J. WS 2 mode-locked ultrafast fiber laser. Sci. Rep. 2015, 5, 7965. [CrossRef]

42. Khazaeinezhad, R.; Kassani, S.H.; Jeong, H.; Park, K.J.; Kim, B.Y.; Yeom, D.I.; Oh, K. Ultrafast pulsed all-fiber laser Based on tapered fiber enclosed by few-layer WS 2 nanosheets. IEEE Photonics Technol. Lett. 2015, 27, 1581-1584. [CrossRef]

43. Luo, Z.; Li, Y.; Zhong, M.; Huang, Y.; Wan, X.; Peng, J.; Weng, J. Nonlinear optical absorption of few-layer molybdenum diselenide $\left(\mathrm{MoSe}_{2}\right)$ for passively mode-locked soliton fiber laser. Photonics Res. 2015, 3, A79-A86. [CrossRef]

44. Shang, C.; Zhang, Y.; Qin, H.; He, B.; Zhang, C.; Sun, J.; Li, J.; Ma, J.; Ji, X.; Xu, L.; et al. Review on wavelength-tunable pulsed fiber lasers based on 2D materials. Opt. Laser Technol. 2020, 131, 106375. [CrossRef]

45. Zhang, H.; Ma, P.; Zhu, M.; Zhang, W.; Wang, G.; Fu, S. Palladium selenide as a broadband saturable absorber for ultra-fast photonics. Nanophotonics 2020, 9, 2557-2567. [CrossRef]

46. Xu, N.; Ma, P.; Fu, S.; Shang, X.; Jiang, S.; Wang, S.; Li, D.; Zhang, H. Tellurene-based saturable absorber to demonstrate large-energy dissipative soliton and noise-like pulse generations. Nanophotonics 2020, 9, 2783-2795. [CrossRef]

47. Mak, K.F.; Lee, C.; Hone, J.; Shan, J.; Heinz, T.F. Atomically thin $\mathrm{MoS}_{2}$ : A new direct-gap semiconductor. Phys. Rev. Lett. 2010, 105, 136805. [CrossRef]

48. Cong, C.; Shang, J.; Wu, X.; Cao, B.; Peimyoo, N.; Qiu, C.; Sun, L.; Yu, T. Synthesis and optical properties of large-area singlecrystalline 2D semiconductor $\mathrm{WS}_{2}$ monolayer from chemical vapor deposition. Adv. Opt. Mater. 2013, 2, 131-136. [CrossRef]

49. Mao, D.; Du, B.; Yang, D.; Zhang, S.; Wang, Y.; Zhang, W.; She, X.; Cheng, H.; Zeng, H.; Zhao, J. Nonlinear saturable absorption of liquid-exfoliated molybdenum/tungsten ditelluride nanosheets. Small 2016, 12, 1489-1497. [CrossRef]

50. Huang, X.; Zeng, Z.; Zhang, H. Metal dichalcogenide nanosheets: Preparation, properties and applications. Chem. Soc. Rev. 2013, 42, 1934. [CrossRef] [PubMed]

51. Zhang, M.; Howe, R.C.T.; Woodward, R.I.; Kelleher, E.J.R.; Torrisi, F.; Hu, G.; Popov, S.V.; Taylor, J.R.; Hasan, T. Solution processed MoS2-PVA composite for sub-bandgap mode-locking of a wideband tunable ultrafast Er:fiber laser. Nano Res. 2015, 8, 1522-1534. [CrossRef]

52. Chen, Y.; Zhao, C.; Chen, S.; Du, J.; Tang, P.; Jiang, G.; Zhang, H.; Wen, S.; Tang, D. Large Energy, Wavelength Widely Tunable, Topological Insulator Q-Switched Erbium-Doped Fiber Laser. IEEE J. Sel. Top. Quantum Electron. 2014, 20, 315-322. [CrossRef]

53. Lee, C.H.; Silva, E.C.; Calderin, L.; Nguyen, M.A.T.; Hollander, M.J.; Bersch, B.; Mallouk, T.E.; Robinson, J.A. Tungsten Ditelluride: A layered semimetal. Sci. Rep. 2015, 5, 10013. [CrossRef]

54. Ali, M.N.; Xiong, J.; Flynn, S.; Tao, J.; Gibson, Q.D.; Schoop, L.M.; Liang, T.; Haldolaarachchige, N.; Hirschberger, M.; Ong, N.P.; et al. Large, non-saturating magnetoresistance in $\mathrm{WTe}_{2}$. Nature 2014, 514, 205-208. [CrossRef]

55. Wang, Q.H.; Kalantar-Zadeh, K.; Kis, A.; Coleman, J.N.; Strano, M.S. Electronics and optoelectronics of two-dimensional transition metal dichalcogenides. Nat. Nanotechnol. 2012, 7, 699-712. [CrossRef]

56. Scholle, K.; Lamrini, S.; Koopmann, P.; Fuhrberg, P. $2 \mu \mathrm{m}$ laser sources and their possible applications. In Frontiers in Guided Wave Optics and Optoelectronics; Pal, B., Ed.; IntechOpen: London, UK, 2010; pp. 471-500.

57. McAleavey, F.J.; O'Gorman, J.; Donegan, J.F.; MacCraith, B.D.; Hegarty, J.; Maze, G. Narrow linewidth, tunable Tm ${ }^{3+}$-doped fluoride fiber laser for optical-based hydrocarbon gas sensing. IEEE J. Sel. Top. Quantum Electron. 1997, 3, 1103-1111. [CrossRef]

58. Ebrahim-Zadeh, M.; Sorokina, I.T. Mid-Infrared Coherent Sources and Applications; Springer: New York, NY, USA, 2008.

59. Spiers, G.D.; Menzies, R.T.; Jacob, J.; Christensen, L.E.; Phillips, M.W.; Choi, Y.; Browell, E.V. Atmospheric $\mathrm{CO}_{2}$ measurements with a $2 \mu \mathrm{m}$ airborne laser absorption spectrometer employing coherent detection. Appl. Opt. 2011, 50, 2098. [CrossRef]

60. Henderson, S.W.; Suni, P.J.M.; Hale, C.P.; Hannon, S.M.; Magee, J.R.; Bruns, D.L.; Yuen, E.H. Coherent laser radar at $2 \mu \mathrm{m}$ using solid-state lasers. IEEE Trans. Geosci. Remote Sens. 1993, 31, 4-15. [CrossRef]

61. Bouma, B.E. Optical coherence tomographic imaging of human tissue at $1.55 \mu \mathrm{m}$ and $1.81 \mu \mathrm{m}$ using er-and tm-doped fiber sources. J. Biomed. Opt. 1998, 3, 76. [CrossRef] [PubMed]

62. Polder, K.D.; Bruce, S. Treatment of melasma using a novel 1,927-nm fractional thulium fiber laser: A pilot study. Dermatol. Surg. 2012, 38, 199-206. [CrossRef] [PubMed]

63. Cizmeciyan, M.N.; Kim, J.W.; Bae, S.; Hong, B.H.; Rotermund, F.; Sennaroglu, A. graphene mode-locked femtosecond Cr:ZnSe laser at $2500 \mathrm{~nm}$. Opt. Lett. 2013, 38, 341. [CrossRef] 
64. Richardson, D.J.; Nilsson, J.; Clarkson, W.A. High power fiber lasers: Current status and future perspectives [Invited]. J. Opt. Soc. Am. B 2010, 27, B63. [CrossRef]

65. Hasan, M.Z.; Kane, C.L. Colloquium: Topological insulators. Rev. Mod. Phys. 2010, 82, 3045-3067. [CrossRef]

66. Jung, M.; Lee, J.; Koo, J.; Park, J.; Song, Y.W.; Lee, K.; Lee, S.; Lee, J.H. A femtosecond pulse fiber laser at 1935 nm using a bulk-structured $\mathrm{Bi}_{2} \mathrm{Te}_{3}$ topological insulator. Opt. Express 2014, 22, 7865. [CrossRef]

67. Kelly, S.M.J. Characteristic sideband instability of periodically amplified average soliton. Electron. Lett. 1992, 28, 806. [CrossRef]

68. Kafka, J.D.; Hall, D.W.; Baer, T. Mode-locked erbium-doped fiber laser with soliton pulse shaping. Opt. Lett. 1989, 14, 1269. [CrossRef] [PubMed]

69. Matsas, V.J.; Richardson, D.J.; Newson, T.P.; Payne, D.N. Characterization of a self-starting, passively mode-locked fiber ring laser that exploits nonlinear polarization evolution. Opt. Lett. 1993, 18, 358. [CrossRef] [PubMed]

70. Tamura, K.; Ippen, E.P.; Haus, H.A.; Nelson, L.E. 77-fs pulse generation from a stretched-pulse mode-locked all-fiber ring laser. Opt. Lett. 1993, 18, 1080. [CrossRef]

71. Ilday, F.Ö.; Buckley, J.R.; Clark, W.G.; Wise, F.W. Self-Similar Evolution of Parabolic Pulses in a Laser. Phys. Rev. Lett. 2004, 92, 213902. [CrossRef] [PubMed]

72. Chong, A.; Buckley, J.; Renninger, W.; Wise, F. All-normal-dispersion femtosecond fiber laser. Opt. Express 2006, $14,10095$. [CrossRef] [PubMed]

73. Grelu, P.; Akhmediev, N. Dissipative solitons for mode-locked lasers. Nat. Photonics 2012, 6, 84-92. [CrossRef]

74. Chang, W.; Ankiewicz, A.; Soto-Crespo, J.M.; Akhmediev, N. Dissipative soliton resonances. Phys. Rev. A 2008, 78, 023830. [CrossRef]

75. Lee, J.; Koo, J.; Lee, J.H. A pulse-width-tunable, mode-locked fiber laser based on dissipative soliton resonance using a bulkstructured $\mathrm{Bi}_{2} \mathrm{Te}_{3}$ topological insulator. Opt. Eng. 2016, 55, 081309. [CrossRef]

76. Zeller, W.; Naehle, L.; Fuchs, P.; Gerschuetz, F.; Hildebrandt, L.; Koeth, J. DFB Lasers Between $760 \mathrm{~nm}$ and $16 \mu \mathrm{m}$ for Sensing Applications. Sensors 2010, 10, 2492-2510. [CrossRef]

77. Fried, N.M.; Murray, K.E. High-Power Thulium Fiber Laser Ablation of Urinary Tissues at 1.94 um. J. Endourol. 2005, 19, 25-31. [CrossRef] [PubMed]

78. Szlauer, R.; Götschl, R.; Razmaria, A.; Paras, L.; Schmeller, N.T. Endoscopic vaporesection of the prostate using the continuouswave 2- $\mu \mathrm{m}$ thulium laser: Outcome and demonstration of the surgical technique. Eur. Urol. 2009, 55, 368-375. [CrossRef] [PubMed]

79. Sobon, G.; Sotor, J.; Pasternak, I.; Krajewska, A.; Strupinski, W.; Abramski, K.M. Thulium-doped all-fiber laser mode-locked by CVD-graphene/PMMA saturable absorber. Opt. Express 2013, 21, 12797. [CrossRef]

80. Lee, J.; Lee, J.; Koo, J.; Lee, J.H. Graphite saturable absorber based on the pencil-sketching method for Q-switching of an erbium fiber laser. Appl. Opt. 2016, 55, 303. [CrossRef]

81. Lin, G.R.; Lin, Y.C. Directly exfoliated and imprinted graphite nano-particle saturable absorber for passive mode-locking erbium-doped fiber laser. Laser Phys. Lett. 2011, 8, 880-886. [CrossRef]

82. Yin, K.; Zhang, B.; Li, L.; Jiang, T.; Zhou, X.; Hou, J. Soliton mode-locked fiber laser based on topological insulator Bi $2 \mathrm{Te}_{3}$ nanosheets at $2 \mu \mathrm{m}$. Photonics Res. 2015, 3, 72. [CrossRef]

83. Jiang, T.; Yin, K.; Wang, C.; You, J.; Ouyang, H.; Miao, R.; Zhang, C.; Wei, K.; Li, H.; Chen, H.; et al. Ultrafast fiber lasers mode-locked by two-dimensional materials: Review and prospect. Photonics Res. 2019, 8, 78. [CrossRef]

84. Li, W.; Peng, J.; Zhong, Y.; Wu, D.; Lin, H.; Cheng, Y.; Luo, Z.; Weng, J.; Xu, H.; Cai, Z. Orange-light passively Q-switched $\mathrm{Pr}^{3+}$-doped all-fiber lasers with transition-metal dichalcogenide saturable absorbers. Opt. Mater. Express 2016, 6, 2031. [CrossRef]

85. Bianchi, V.; Carey, T.; Viti, L.; Li, L.; Linfield, E.H.; Davies, A.G.; Tredicucci, A.; Yoon, D.; Karagiannidis, P.G.; Lombardi, L.; et al. Terahertz saturable absorbers from liquid phase exfoliation of graphite. Nat. Commun. 2017, 8, 15763. [CrossRef] [PubMed] 